\title{
Optimal Risk Financing in Large Corporations through Insurance Captives
}

\author{
Pierre Picard ${ }^{\mathrm{a}}$ and Jean Pinquet ${ }^{\mathrm{a}, \mathrm{b}}$ \\ ${ }^{a}$ Department of Economics, Ecole Polytechnique, route de Saclay, 91128, Palaiseau Cedex, France. \\ E-mail: pierre.picard@polytechnique.edu \\ ${ }^{\mathrm{b}}$ Université Paris-Ouest Nanterre La Défense. \\ E-mail: jean.pinquet@polytechnique.edu
}

A captive is an insurance or reinsurance company established by a parent group to finance its own risks. Captives mix internal risk pooling between the business units of the parent group and risk transfer towards the reinsurance market. We analyse captives from an optimal insurance contract perspective. The paper characterises the vertical contractual chain that links firstly business units to insurance captives or to "fronters" through insurance contracts, secondly fronters to reinsurance captives through the cession of risks and thirdly insurance or reinsurance captives to reinsurers through cessions or retrocessions. In particular, the risk cession by fronters to a reinsurance captive trades off the benefits derived from recouped premiums and from the risk-sharing advantage of an "umbrella reinsurance policy", against the risks that result from the captive liabilities.

The Geneva Risk and Insurance Review (2013) 38, 48-86. doi:10.1057/grir.2012.4

Keywords: insurance captives; risk management; reinsurance; contract

\section{Introduction}

A captive is an insurance or reinsurance company established by a parent group to finance its own risks. Captive insurance thus provides a risk management technique to finance the retained losses of a corporation in a separate legal entity. The captive insurance industry has its origin in the formation of mutuals and coinsurance companies in the 1920s and 1930s in the U.S. However, the real growth of the captive industry began in the 1960s and the move by parent companies to establish their captives offshore, particularly in the Bermuda market. The 1970s and 1980s were a period of tremendous growth of the captive industry. The greatest stimulus was the cost or lack of availability of certain types of insurance cover in the commercial lines, particularly liability coverage. Many other considerations apply and the interest in captives is now greater than ever. A captive carries out all the functions of a standard insurance or reinsurance company. It issues policies to its insured or reinsures a fronting insurance company, collects the premiums and pays the claims. 
It sets aside reserves to pay its legal obligations arising from the insurance and reinsurance agreements, pays for its operating expenses and pays dividends to its insured/owners. It earns investment income on the invested assets. ${ }^{1}$

There are many reasons for which a corporation decides to create a captive. ${ }^{2}$ Captives allow the parents to mitigate the fluctuations of insurance costs and to save costs by eliminating brokers fees, reducing transaction costs and avoiding costly insurance regulations. Captives can also access the capacity of reinsurance markets with lower wholesale prices and higher limits of coverage than in the retail market. Captives may provide the cover when the commercial market is unable or unwilling to underwrite certain risks or when the price quoted is seen to be unreasonable. They also allow parents to benefit from better than average claim experience. Recapturing investment income and managing cash flows is another frequently mentioned motive for creating a captive. Although taking advantage of tax deductibility is no more the main advantage of captives, there are still tax advantages to be gained by using captives. $^{3}$ A captive can also act as a focus for risk management activities, particularly by providing its parent with a data warehouse to support its risk prevention efforts (e.g. about accidents at work and workers' compensation). Finally, captives allow large corporations to fund the difference between their large corporate retention and the relatively small deductibles sought by the firm's individual business units. On the negative side, regulation or parents' shortage of capital may sometimes dampen enthusiasm for captives. ${ }^{4}$

${ }^{1}$ The world's total number of captives was 5,290 in 2009 according to Business Insurance's annual captive survey. Most major corporations now own one or several captives. There are several types of insurance captives, including single-parent captive, group captive, rent-a-captive, protected cell captive and agency captive, most of them making their home offshore; see Banks (2004).

${ }^{2}$ Scordis and Porat (1998) argue that the creation of captives enhances the status of the risk manager and test the hypothesis that corporations with heightened manager-owner conflicts of interest are more likely to operate a single-parent captive. They find that captive creation increases with the size of the firm, but decreases with Tobin's q (the ratio between the market value of the firm and the replacement value of net assets), which is seen as a proxy for managerowner conflicts. Smith (1986), Cross et al. (1988), Han and Lai (1991) and Lai and Witt (1995) focus on the tax deductibility issue of captive insurance premiums. Diallo and Kim (1989) stress the aforementioned advantages of captive creation as a way to reach a better monitoring of risk prevention activities of the parent's business units.

${ }^{3}$ Cross et al. (1988) show that captive creation in the U.S.A. created value until 1978, the year after which most tax advantages disappeared.

${ }^{4}$ For example, in a special report on European Captive Insurance, A.M. Best (2009) observes that "some captives will be forced to close as they fail to comply with the new Solvency II Directive by the Oct.31, 2012 deadline 'and that' the credit crisis has led some parent companies to tap their captives for cash", and concludes that "the (European) captive market will continue to develop in the face of its current challenges, although the growth will shift toward the formation of cells rather than the creation of pure captives". 
Captives mix internal risk pooling between the business units of the parent group (thereby improving the parent's self-insurance capacity) and risk transfer towards the reinsurance market. The objective of the present paper is to analyse this mechanism from an optimal insurance contract perspective. Two stylised facts will be in the background of our analysis. Firstly, cessions to captives are substitutes for contingency and loss provisions and therefore they are targeted at lower risk layers. Put it differently, insurance and reinsurance captives work as expansion tanks of parent groups' self insurance capacity and they typically cede or retrocede higher risk tiers to reinsurance markets. In particular, they can offer some form of "umbrella policy" to their parent group. ${ }^{5}$ The aim of this paper is to analyse how such expansion tanks and umbrella policies can improve the risk sharing between parent groups and insurance or reinsurance firms. Secondly, it has been extensively documented that insurance markets are characterised by alternating periods of hard markets with relatively high prices and limited capacity and soft markets with relatively low prices and plentiful supply. ${ }^{6}$ Captives' activity reacts to this insurance underwriting cycle. In particular, casual observation suggests that parent groups have used their captives more intensely when corporate insurance became more expensive or even unavailable after shocks, particularly in the 1980s for liability lines or in the post-Katrina period. Conversely, parent groups may keep their captives dormant in soft market periods. ${ }^{7}$ Furthermore, the activity of captives is also affected by wealth effects: a larger amount of corporate capital available in parent groups provides additional capacity for self-insurance and is thus likely to induce a more intense use of captives. Conversely, the activity of captives may slow down after a financial shock reduced the parents' self-insurance capacity. ${ }^{8}$ We also aim to understand how such variations in insurance prices and corporate capital may affect the design of the optimal captive arrangement.

The paper is organised as follows. The next section presents the model. We consider a firm made up of a number of decentralised business units that may

${ }^{5}$ In an umbrella policy the indemnity is a deterministic function of the aggregate loss incurred by the insured (see Gollier, 2000). This is what a holding company can manage through an insurance or reinsurance captive that will cede or retrocede the holding's aggregate risk to reinsurers.

${ }^{6}$ See Cummins and Doherty (2002).

${ }^{7}$ Scordis et al. (2007) use Monte Carlo simulation to identify conditions under which captives have a high probability of creating positive shareholder value, even without favourable tax treatment. They show that the main feature of a well-managed captive is flexibility: such a captive is incorporated in the least costly captive jurisdiction during a soft insurance market, but remains dormant until a hard insurance market.

${ }^{8}$ This is illustrated by recent trends in captive markets: according to Business Insurance (2010, $8 \mathrm{March}$ ), in 2009 many parent companies have tapped their captives to enhance corporate capital. 
be subject to insurable losses. Stabilising the current cash flow of each business unit improves the value of the firm because it is costly to transfer cash between business units in response to profitability shocks and because, in addition, the marginal cost of external capital is increasing. Business units purchase insurance from market insurers and/or from a captive insurance company created by the firm. Market insurers may also act as "fronters": they partly or fully cede the underwritten risks to the captive, which then acts as a reinsurer and possibly retrocedes the risks to market reinsurers. The latter two sections respectively focus on insurance and reinsurance captives. We shall conclude that reinsurance captives dominate insurance captive for reasonable assumptions on cost parameters. Intuitively a reinsurance captive allows the parent to cumulate the advantage of an "umbrella policy" through its retrocession activity with the lower underwriting and claims handling costs of fronters. We analyse the vertical contractual chain that links business units to fronters or directly to the captive through insurance policies, fronters to the reinsurance captive through the cession of risks and the captive to reinsurers through cession or retrocession. The risk cession by fronters to the reinsurance captive trades off the benefits derived from recouped premiums and from the risk-sharing advantage of an umbrella reinsurance policy, against the risks that result from the captive liabilities. The optimal mechanism involves full cession of risks by the fronter to the captive up to an upper limit, possibly with partial cession over this limit. Furthermore, business units should have partial insurance at the margin in order to reach an optimal risk sharing with the captive. The optimal insurance or reinsurance captive scheme depends on various parameters, including the cost of capital in insurance markets, the reinsurance loading factor and the parent group's corporate capital. Variations in these parameters may trigger changes in the intensity of the captive activity. Numerical examples illustrate these price and wealth effects in the penultimate section. The last section concludes. All proofs are in the Appendix.

\section{The model}

We consider a corporation organised as a holding company, which is made up of $n$ business units indexed by $i=1, \ldots, n$. Each business unit is a subsidiary of the holding company with specific location and activity. Let $\Pi_{i}$ be the sum of initial endowment and cash flows of unit $i$ during the current period. For unexpected low values of $\Pi_{i}$ unit $i$ may have to call up external capital or to delay profitable investment projects. In both cases, insufficient current cash flows entail additional costs and lower current or future profits. We assume that these induced losses occur at an increasing marginal rate because when 
current cash flows are decreasing then either the cost of external additional capital is increasing or more profitable projects have to be postponed. To capture these two effects of current cash flows on the value of the firm, we write the contribution of unit $i$ to the shareholder value of the holding company (i.e. its consolidated expected discounted profits) as $W_{i}=B_{i}\left(\Pi_{i}\right)$, where $B_{i}$ is an increasing strictly concave function, that is, $B_{i}^{\prime}\left(\Pi_{i}\right)>0, B_{i}^{\prime \prime}\left(\Pi_{i}\right)<0$. The concavity of $B_{i}$ will provide a rationale for stabilising the short-term income of unit $i .^{9}$ This argument rests on the implicit assumption that the holding company cannot transfer cash between business units during the current period. Picard and Pinquet (2011) show how our model can be extended to a more realistic framework where intraperiod transfers between business units are feasible but costly. ${ }^{10}$

The current cash flows of business units may be affected by losses that can be covered by insurance contracts. Insurance can be taken out either in the insurance market (say from local insurers ${ }^{11}$ ) or from a captive created by the holding company. For the time being, we assume that the captive only acts as direct insurer of business units. The role of a reinsurance captive will appear in Section "Fronting and reinsurance captives". Let $w_{i}$ be the initial wealth of unit $i$, that is, the sum of initial endowment and current cash flows, excluding insurable losses and insurance financial transfers: $w_{1}, \ldots, w_{n}$ are deterministic parameters and $\sum_{i=1}^{n} w_{i}$ may be viewed as the parent's group corporate capital. ${ }^{12}$ Let $\tilde{x}_{i}$ be the insurable losses of unit $i$. The variables $\tilde{x}_{i}, i=1 \ldots, n$ are random and independently distributed over intervals $\left[0, \bar{x}_{i}\right]$ with cumulative distribution functions $\Phi_{i}\left(x_{i}\right)$. They have densities $\varphi_{i}\left(x_{i}\right) \equiv \Phi_{i}^{\prime}\left(x_{i}\right)$ over $\left(0, \bar{x}_{i}\right]$ and point masses of probability at $x_{i}=0$.

${ }^{9}$ See Miller and Orr (1966), Meltzer (1963) and Mulligan (1997) on the cost of being short liquid assets and having to cut investment or raise external funds. Following Froot et al. (1993) we could derive this rationale for corporate hedging from an agency-based approach. See Chapter 6 in Tirole (2006) for further developments.

${ }^{10}$ Such transfers may be difficult on a short-term basis either because of regulatory restraints or due to contractual provisions, for example, in case of restrictions on currency exchange or when international transfers require the approval of local partners when a business unit is a joint venture. Even if transferring money is feasible, it will usually induce transaction costs and it may perturbate the firm's tax optimisation or the dividend distribution strategy. Transferring money between business units in an unexpected way may also perturbate incentive mechanisms and it may exacerbate transitory liquidity problems thereby inducing additional costs. Hartzell et al. (2006) find empirical support for both transaction costs and precautionary motives to explain why U.S. multinational firms hold cash, but they also find evidence consistent with tax costs associated with repatriating foreign income driving firms to hold more cash.

${ }^{11}$ The terminology "local insurer" is used only for the sake of clarity but such insurers may be subsidiaries of the same insurance company, and in practice this is often the case.

${ }^{12} w_{1}, \ldots, w_{n}$ are given but all that matters is $\sum_{i=1}^{n} w_{i}$ because capital can be reallocated between business units at the beginning of the current period. See the role of variables $k_{1}, \ldots, k_{n}$ below. 
Indemnity schedules $I_{i}\left(x_{i}\right)$ and $t_{i}\left(x_{i}\right)$ specify the payment made to unit $i$ respectively by the local insurer (say by insurer $i^{13}$ ) and by the captive, as a function of realised losses $x_{i} . I_{i}\left(x_{i}\right)$ and $t_{i}\left(x_{i}\right)$ are non-decreasing functions defined over $\left[0, \bar{x}_{i}\right]$. Let $P_{i}$ and $k_{i}$ be the corresponding insurance premiums paid by unit $i$ respectively to insurer $i$ and to the captive. ${ }^{14}$ We thus have ${ }^{15}$

$$
\Pi_{i}=w_{i}-x_{i}+I_{i}\left(x_{i}\right)-P_{i}+t_{i}\left(x_{i}\right)-k_{i} \text { for all } i=1, \ldots, n .
$$

The risks underwritten by the captive may be ceded through a reinsurance contract which provides payment $T\left(t_{1}, \ldots, t_{n}\right)$ to the captive as a function of the transfers made to the business units, with the cession of premiums $Q$ to reinsurers. Let $A^{\ell} \subset\{1, \ldots, n\}$ denotes the set of business units insured by local insurers (i.e. such that $I_{i}\left(x_{i}\right)>0$ with positive probability), with $P_{i}=0$ if $i \notin A^{\ell}$. Similarly, let $A^{c} \subset\{1, \ldots, n\}$ be the set of business units insured by the captive (i.e. such that $t_{i}\left(x_{i}\right)>0$ with positive probability). ${ }^{16}$ This is illustrated by Figure 1 in the case where $A^{\ell} \cap A^{c}=\emptyset$.

Local insurers and the captive bear fixed underwriting costs. Operating in market $i$, that is, in the area of activity of business unit $i$, requires incurring fixed costs $f_{i}$ for local insurer $i$ and $\widehat{f}_{i}$ for the captive (respectively when $I_{i}\left(x_{i}\right)>0$ and $t_{i}\left(x_{i}\right)>0$ with positive probability). ${ }^{17}$ Insurance and reinsurance costs also include variable costs (claims handling costs and capital costs) which take the form of loadings at rate $\lambda_{i}$ for local insurer $i$ and $\mu$ for reinsurers. We assume

${ }^{13}$ For notational simplicity index $i$ thus simultaneously refers to a specific business unit and to its local insurer.

${ }^{14}$ For simplicity we refer to $k_{i}$ as a "premium" although it includes all forms of financial transfer from business unit $i$ to the captive. Tax issues are completely ignored in this model, which makes this aggregation of financial flows possible.

${ }^{15}$ Our analysis can easily be extended to the case where the cashflows of business units are affected by independent additive background risks, be they financial or technological. The sum of initial endowment and current casflows of unit $i$ may indeed be written as $\Pi_{i}+\varepsilon_{i}$ where $\Pi_{i}$ is given by (1) and $\varepsilon_{i}$ is an independent zero-mean background risk incurred by business unit $i$. In that case, $B_{i}\left(\Pi_{i}\right)$ should be replaced by $\tilde{B}_{i}\left(\Pi_{i}\right) \equiv E_{\varepsilon_{i}} B_{i}\left(\Pi_{i}+\varepsilon_{i}\right)$ with no substantial effect on our analysis and our conclusions.

16 The holding company may find that it is optimal to recapitalise the captive by transfering money from business units that buy insurance only from local insurers. We thus may have $k_{i} \neq 0$ even if $i \notin A^{c}$. We may have $A^{\ell} \cap A^{c} \neq \emptyset$, that is, some business units may buy insurance at the same time from local insurers and from the captive.

${ }^{17}$ Direct insurers can spread such fixed costs among several customers (at least if there are other firms operating in the same area of activity that purchase insurance from insurer $i$ ) while the captive only underwrites the risks of its parent's subsidiaries. Consequently, local insurers enjoy underwriting economies of scale by comparison with the captive, which suggests that we should have $f_{i}<\widehat{f}_{i}$. However, the captive insurer may be specialised in the type of risk run by the corporation, which may be the source of an information advantage over the local insurers, hence lower underwriting costs and thus possibly $\widehat{f}_{i}<f_{i}$ in such a case. 


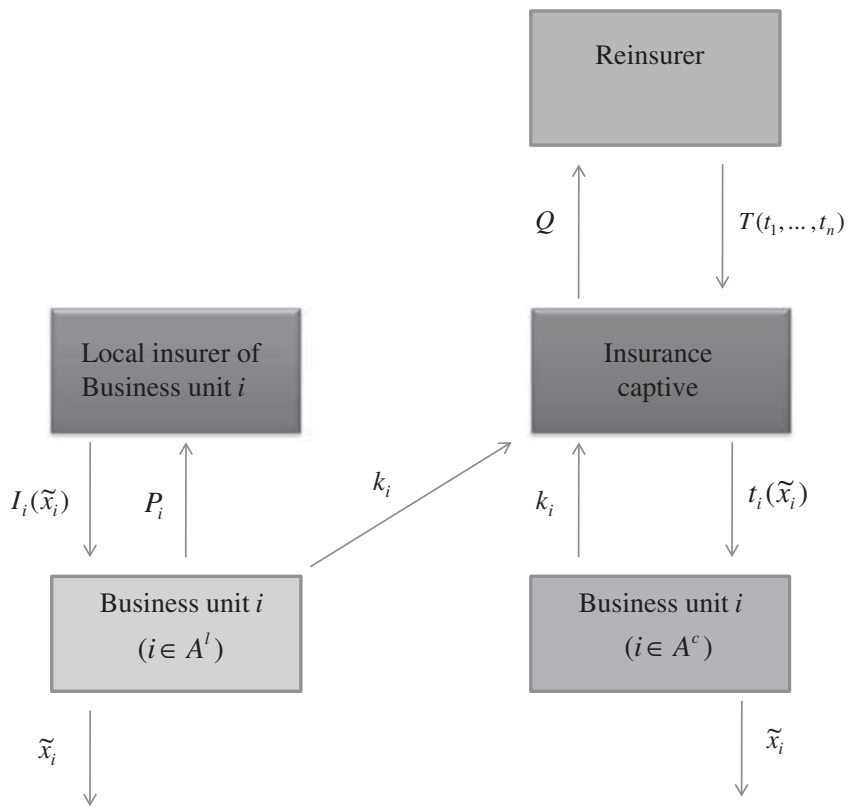

Figure 1. Insurance captive.

that claim handling costs are proportional to the amount of claims, while capital costs are proportional to the losses that are retained by the insurer. ${ }^{18}$ We break down the insurer $i$ 's loading factor by writing $\lambda_{i}=\lambda_{i}^{c}+\lambda_{i}^{k}$, where $\lambda_{i}^{c}$ refers to the claims handling cost, while $\lambda_{i}^{k}$ correspond to capital costs. Because of competitive pressure, insurance premiums charged by local insurers and reinsurers just cover expected costs, including fixed underwriting costs and variable costs. We thus have

$$
\begin{gathered}
P_{i}=\left(1+\lambda_{i}^{c}+\lambda_{i}^{k}\right) E\left[I_{i}\left(\tilde{x}_{i}\right)\right]+f_{i} \quad \text { if } i \in A^{\ell} \\
Q=(1+\mu) E\left[T\left(t_{1}\left(\tilde{x}_{1}\right), \ldots, t_{n}\left(\tilde{x}_{n}\right)\right)\right] .
\end{gathered}
$$

The captive also incurs variable costs, which include claim handling costs proportional to the amount of filed claims at rate $\hat{\lambda}_{i}^{c}$ and capital cost. The capital cost corresponds to the opportunity cost of transferring

${ }^{18}$ Risk cession by local insurers to the captive will be considered in Section "Fronting and reinsurance captives". 
financial resources from the business units to the captive through insurance premium $k_{i}$, which is reflected by functions $B_{i}($.$) . For notational simplicity,$ we assume that the captive has no initial endowment. Its current profit is written as

$$
\Pi_{0}=\sum_{i=1}^{n} k_{i}-\sum_{i \in A^{c}}\left[\left(1+\widehat{\lambda}_{i}^{c}\right) t_{i}\left(x_{i}\right)+\widehat{f}_{i}\right]+T\left(t_{1}\left(x_{1}\right), \ldots, t_{n}\left(x_{n}\right)\right)-Q
$$

When $\Pi_{0}$ is low, the captive breaks even by calling up external capital at an increasing marginal cost. Similarly to business units, the contribution of the captive to the holding company's shareholder value is thus written as $W_{0}=B_{0}\left(\Pi_{0}\right)$, with $B_{0}^{\prime}\left(\Pi_{0}\right)>0, B^{\prime \prime}{ }_{0}\left(\Pi_{0}\right)<0 .{ }^{19}$

An insurance captive scheme $\left\{I_{i}\left(x_{i}\right), P_{i}, t_{i}\left(x_{i}\right), k_{i}\right.$ for $\left.i=1, \ldots, n ; T\left(t_{1}, \ldots, t_{n}\right), Q\right\}$ is feasible if it satisfies (2) and (3). The holding company chooses a feasible insurance scheme that maximises its expected consolidated shareholder value $W$, which comes additively from the business units and from the captive. The shareholder value may thus be written as

$$
W=E\left[\sum_{i=0}^{n} W_{i}\right]=E\left[\sum_{i=0}^{n} B_{i}\left(\Pi_{i}\right)\right],
$$

where $\Pi_{0}$ and $\Pi_{1}, \ldots, \Pi_{n}$ are respectively given by (4) and (1). ${ }^{20}$

\section{Optimal insurance captive schemes}

Corporations that use an insurance captive trade off the benefits associated with an umbrella reinsurance policy against costs which may be larger for the captive than for local insurers. Obviously, when local insurer $i$ is faced with larger variable and fixed costs than the captive, then business unit $i$ should purchase insurance only from the captive.

\footnotetext{
${ }^{19}$ The concavity of function $B_{0}\left(\Pi_{0}\right)$ conveys the risk aversion of the holding company w.r.t. the captive's cash flows, with the same capital market rationale behind this assumption as for business units. See Froot and Stein (1998) and Froot (2007) on financial institutions' risk management when fluctuations in internal cash result in fluctuations in costs of raising external funds.

${ }^{20}$ The present modelling can easily be extended to the case where the holding company can transfer funds between business units during the current period, but such transfers induce transaction costs. See the working paper version of this article: Picard and Pinquet (2011).
} 
When this is not the case, the balance may tip in favour of the captive or the local insurer. A business unit may even purchase insurance from both sources.

Proposition 1 An optimal insurance captive scheme specifies that all business units $i$ such that $(1+\mu)\left(1+\widehat{\lambda}_{i}^{c}\right) \leqslant 1+\lambda_{i}$ and $\widehat{f}_{i} \leqslant f_{i}$ purchase insurance only from the captive, while other units may purchase insurance from the captive and/or from the local insurer. The captive cedes a part of the underwritten risk through a stop-loss reinsurance contract $T\left(t_{1}, \ldots, t_{n}\right) \equiv\left[\sum_{i=1}^{n}\left(1+\hat{\lambda}_{i}^{c}\right) t_{i}-D\right]^{+}$, with $D>0$ and $x^{+}=\max (x, 0)$.

Let us start commenting on Proposition 1 with its second part. The captive should cede its aggregate loss $\sum_{i=1}^{n}\left(1+\hat{\lambda}_{i}^{c}\right) t_{i}$ (claims handling cost included) through a reinsurance stop-loss contract with deductible $D$. This is analogous to the optimality of straight deductible contracts in the case of insurance demand by a risk-averse individual under constant loading. Through its reinsurance contract, the insurance captive provides an umbrella policy to the holding company, that is, a cover for the aggregate loss $\sum_{i=1}^{n}\left(1+\hat{\lambda}_{i}^{c}\right) t_{i}$, which may be more efficient than independent coverage separately obtained by business units from local insurers.

This efficiency gain associated with the captive umbrella policy may be annihilated if the captive is subject to higher costs than local insurers, and the first part of Proposition 1 gives sufficient conditions for covering the risk through the captive to be optimal. These conditions are more easily interpreted if we observe that $(1+\mu)\left(1+\widehat{\lambda}_{\mathrm{i}}^{\mathrm{c}}\right) E\left[I_{i}\left(\tilde{x}_{i}\right)\right]$ is the captive's variable cost for risks that are ceded to reinsurers, while $\left(1+\lambda_{i}\right) E\left[I_{i}\left(\tilde{x}_{i}\right)\right]$ denotes the local insurer variable cost. If fixed underwriting costs $f_{i}$ and $\widehat{f}_{i}$ are large enough for purchasing insurance simultaneously from the local insurer and from the captive to be suboptimal, then business units are split between two groups (i.e. $A^{\ell} \cap A^{c}=\emptyset$ as represented in Figure 1) according to whether or not the benefits of a better risk sharing through an umbrella policy are larger than the increase in fixed underwriting costs (when $\widehat{f}_{i}>f_{i}$ ) and/or variable costs (when $(1+\mu)\left(1+\hat{\lambda}_{i}^{c}\right)>1+\lambda_{i}$ ). When the balance tips in favour of the risk-sharing advantage, then the business units should be insured by the captive, while they should be insured by local insurers in the other case.

Remark 1 As an illustration of Proposition 1, observe that condition $(1+\mu)\left(1+\hat{\lambda}_{i}^{c}\right)<1+\lambda_{i}$ is approximately equivalent to $\lambda_{i}^{k}-\mu>\hat{\lambda}_{i}^{c}-\lambda_{i}^{c}$ for small loading factors. The right-hand side of this inequality corresponds to differences in claim handling costs between the captive and local insurer $i$ and we 
may consider it as a structural efficiency gap. The left-hand side is directly affected by changes in the cost of capital and in the reinsurance loading. We may then think of hard market situations where the underwriting capacity of direct insurers is limited because they meet difficulties in raising additional capital, which result in an increase in $\lambda_{i}^{k}$. For given state of reinsurance market (i.e. for $\mu$ unchanged) transferring the business units risk to the captive is then more likely to be an optimal choice in hard markets than in soft market periods where $\lambda_{i}^{k}$ would be lower. Put differently, if local insurer $i$ has experienced adverse underwriting conditions in year $t$, then it is likely to have a higher cost of capital $\lambda_{i}^{k}$ in year $t+1$, with more cessions to captives. This is all the more likely given that the adverse shocks have been specific for insurer $i$ and did not come with a hard reinsurance market. $^{21}$

We now turn to the characterisation of the optimal insurance coverage offered by the captive and local insurers. Substituting $T\left(t_{1}, \ldots, t_{n}\right)=$ $\left[\sum_{i=1}^{n}\left(1+\hat{\lambda}_{i}^{c}\right) t_{i}-D\right]^{+}$in (3) and (4), the optimal insurance captive scheme maximises

$$
\begin{aligned}
W= & E\left[B_{0}\left(\sum_{i=1}^{n} k_{i}-\min \left\{\sum_{i \in A^{c}}\left(1+\hat{\lambda}_{i}^{c}\right) t_{i}\left(\tilde{x}_{i}\right), D\right\}-\sum_{i \in A^{c}} \widehat{f}_{i}-Q\right)\right], \\
& +\sum_{i=1}^{n} E\left[B_{i}\left(w_{i}-\tilde{x}_{i}+I_{i}\left(\tilde{x}_{i}\right)-P_{i}+t_{i}\left(\tilde{x}_{i}\right)-k_{i}\right)\right]
\end{aligned}
$$

with respect to $k_{i}, P_{i}$ and $I_{i}(),. t_{i}() \geqslant$.0 for all $i$ and $D \geqslant 0$ subject to (2) and

$$
Q=(1+\mu) E\left[\left\{\sum_{i=1}^{n}\left(1+\widehat{\lambda}_{i}^{c}\right) t_{i}\left(\tilde{x}_{i}\right)-D\right\}^{+}\right] .
$$

Proposition 2 characterises the optimal insurance captive mechanism when fixed underwriting costs lead each business unit to buy insurance either from the local insurer or from the captive, but not from both simultaneously.

${ }^{21}$ The analysis of Weiss and Chung (2004) and Meier and Outreville (2006) suggests that the price of coverage in insurance and reinsurance markets do not move in a perfectly synchronised way. As observed by Scordis et al. (2007), this creates an arbitrage opportunity, which allows firms possessing insurance captives to shop across two markets, and also to treat the captive as a source of flexibility when the insurance market hardens. 
Proposition 2 When $A^{\ell} \cap A^{c}=\emptyset$, an optimal insurance captive scheme is defined by $d_{i}^{0}, d_{i}^{1}>0$ such that

$$
\begin{aligned}
I_{i}\left(x_{i}\right) & =\left(x_{i}-d_{i}^{0}\right)^{+} & & \text {if } i \in A^{\ell}, \\
t_{i}\left(x_{i}\right) & =0 & & \text { if } x_{i} \leqslant d_{i}^{1} \text { and } \\
\mathrm{d} t_{i}\left(x_{i}\right) / \mathrm{d} x_{i} & \in(0,1) & & \text { if } x_{i}>d_{i}^{1} \text { if } i \in A^{c} .
\end{aligned}
$$

The optimal insurance coverage obtained from local insurers is a straight deductible contract, that is, local insurer $i$ fully covers the losses above the deductible $d_{i}^{0}$ if $i \in A^{\ell}$. This is a well-known optimal insurance characterisation under constant loading and there is nothing new here. As for the captive, it offers coinsurance coverage to business units $i$ in $A^{c}$ when losses exceed threshold $d_{i}^{1}$. As shown in the proof of Proposition 2, a positive optimal transfer $t_{i}\left(x_{i}\right)$ equalises the expected marginal value of cash in business unit $i$ and in the captive. This equality may be written as

$$
B_{i}^{\prime}\left(w_{i}-x_{i}+t_{i}\left(x_{i}\right)-k_{i}\right)=\left(1+\widehat{\lambda}_{i}^{c}\right) E\left[B_{0}^{\prime}\left(\Pi_{0}\right) \mid t_{i}\left(x_{i}\right)\right],
$$

where $E\left[B^{\prime}{ }_{0}\left(\Pi_{0}\right) \mid t_{i}\left(x_{i}\right)\right]$ denotes the expected marginal value of an increase in the captive profit conditionally on $t_{i}\left(x_{i}\right){ }^{22}$ We have $\partial E\left[B^{\prime}{ }_{0}\left(\Pi_{0}\right) \mid t_{i}\right] / \partial t_{i}>0$ because $B_{0}($.$) is a concave function and an increase in t_{i}$ decreases the captive expected cash flows anything else given, because of the reinsurance deductible $D$. Differentiating (7) and using $B^{\prime \prime}{ }_{i}<0$ then gives $\mathrm{d} t_{i}\left(x_{i}\right) / \mathrm{d} x_{i} \in(0,1)$. Note that $D=0$ would be optimal if $\mu=0$. We would have $\mathrm{d} t_{i}\left(x_{i}\right) / \mathrm{d} x_{i}=1$ in that case, which highlights the fact that the coinsurance arrangement between the captive and the business units arises from the reinsurance loading. The proof of Proposition 2 also shows that it would be optimal to cover losses of any size if $\widehat{\lambda}_{i}^{c}=0$, but because of the captive claims handling costs small losses should not be covered, that is, we have $d_{i}^{1}>0$. We thus have a clear-cut connection between the captive cost factors and the shape of its indemnity schedule: firstly business units should receive partial coverage "at the margin" because the captive is subject to reinsurance costs and secondly small losses should be retained because of claims handling costs.

\footnotetext{
${ }^{22}$ In $E\left[B^{\prime}{ }_{0}\left(\Pi_{0}\right) \mid t_{i}\left(x_{i}\right)\right]$ the expected value operator is with respect to transfers from the captive to all local insurers $j \neq i$ by taking into account the captive's reinsurance. See the proof of Proposition 2 in the Appendix.
} 


\section{Fronting and reinsurance captives}

Let us come back to our general model and assume now that the captive can also act as a reinsurer, with local insurers behaving as fronters for the business units. The cession of risks by insurer $i$ to the captive is written as $C_{i}\left(I_{i}\right), K_{i}$ where $C_{i}\left(I_{i}\right)$ refers to the transfer from the captive to insurer $i$ as a function of losses $I_{i}$, with $0 \leqslant C_{i}\left(I_{i}\right) \leqslant I_{i}$ and $K_{i}$ is the amount of premium ceded to the captive. ${ }^{23}$ With such cessions, the claims handling costs incurred by local insurer $i$ are still proportional to the amount of claims $I_{i}\left(x_{i}\right)$ as before, but now capital costs are proportional to retained claims $I_{i}\left(x_{i}\right)-C_{i}\left(I_{i}\left(x_{i}\right)\right)$ since no capital allocation is required for ceded risks. Because of competitive pressures, ceded premiums are equal to the decrease in local insurers' capital cost induced by cessions. We thus have

$$
K_{i}=\left(1+\lambda_{i}^{k}\right) E C_{i}\left(I_{i}\left(\tilde{x}_{i}\right)\right)
$$

The captive cedes or retrocedes risks through a reinsurance contract that specifies a transfer to the captive $T\left(t_{1}, \ldots, t_{n}, C_{1}, \ldots, C_{n}\right)$ as a function of the payments to business units $t_{1}, \ldots, t_{n}$ and to local insurers $C_{1}, \ldots, C_{n}$, with $C_{i}=C_{i}\left(I_{i}\right)$ for all $i$. We thus have

$$
Q=(1+\mu) E\left[T\left(t_{1}\left(\tilde{x}_{1}\right), \ldots, t_{n}\left(\tilde{x}_{n}\right), C_{1}\left(I_{1}\left(\tilde{x}_{1}\right)\right), \ldots, C_{n}\left(I_{n}\left(\tilde{x}_{n}\right)\right)\right] .\right.
$$

The captive's profit is now written as

$$
\begin{aligned}
\Pi_{0}= & \sum_{i=1}^{n} k_{i}-\sum_{i \in A^{c}}\left[\left(1+\widehat{\lambda}_{i}^{c}\right) t_{i}\left(x_{i}\right)+\widehat{f}_{i}\right]+\sum_{i \in A^{\ell}}\left[K_{i}-C_{i}\left(I_{i}\left(x_{i}\right)\right)\right] \\
& +T\left(t_{1}\left(x_{1}\right), \ldots, t_{n}\left(x_{n}\right), C_{1}\left(I_{1}\left(x_{1}\right)\right), \ldots, C_{n}\left(I_{n}\left(x_{n}\right)\right)\right)-Q,
\end{aligned}
$$

where $A^{c}$ and $A^{\ell}$ still respectively denote the set of business units that are directly insured by the captive or by local insurers.

An insurance-reinsurance captive scheme is now written as $\left\{I_{i}\left(x_{i}\right), P_{i}, t_{i}\left(x_{i}\right)\right.$, $k_{i}, C_{i}\left(I_{i}\right), K_{i}$ for $\left.i=1, \ldots, n ; T\left(t_{1}, \ldots, t_{n}, C_{1}, \ldots, C_{n}\right), Q\right\}$. It is feasible if it satisfies (2), (8) and (9). An optimal insurance captive scheme maximises

${ }^{23}$ In the reinsurance terminology, this is a non-proportional reinsurance mechanism. In the present setting, ignoring any underwriting commission, proportional reinsurance would correspond to the particular case where $C_{i}\left(I_{i}\right)=c_{i} I_{i}$ and $K_{i}=c_{i} P_{i}$, with $c_{i} \in[0,1]$ the cession rate. In practice, local insurers may also simultaneously purchase reinsurance from reinsurers apart from the captive. 


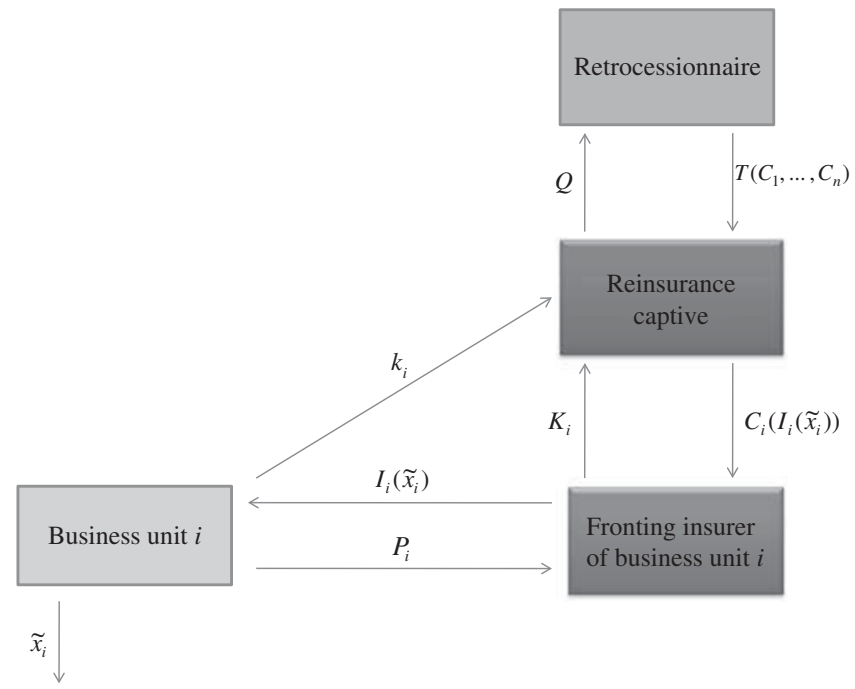

Figure 2. Reinsurance captive.

$W=E\left[\sum_{i=0}^{n} B_{i}\left(\Pi_{i}\right)\right]$, where $\Pi_{0}$ and $\Pi_{1}, \ldots, \Pi_{n}$ are respectively given by (10) and (1).

Proposition 3 shows that the optimal risk-sharing mechanism takes a simple form when local insurers have lower claim handling costs and underwriting costs than the captive. Indeed using local insurers as fronters allows the parent group to cumulate the advantages of an umbrella policy through the retrocession of risks by the captive and the benefits of lower claim handling and underwriting costs, while the direct insurers capital costs can be recouped through ceded premiums. Proposition 3 is illustrated with Figure 2: all the claims go through the local insurers who act as fronters and the captive only acts as a reinsurer.

Proposition 3 An optimal insurance-reinsurance captive scheme specifies that $t_{i}\left(x_{i}\right) \equiv 0$ for all $i$ such that $\lambda_{i}^{c} \leqslant \widehat{\lambda}_{i}^{c}(1+\mu)$ and $f_{i} \leqslant \widehat{f}_{i}$, that is, when variable claim handling costs and fixed underwriting costs are lower for local insurers than for the captive, then local insurers are fronters: the business units purchase insurance from local insurers only. The captive retrocedes a part of the underwritten risks through a stop-loss reinsurance contract $T\left(C_{1}, \ldots, C_{n}\right) \equiv$ $\left(\sum_{i=1}^{n} C_{i}-D\right)^{+}$, with $D>0$.

From now on we will assume $\lambda_{i}^{c} \leqslant \widehat{\lambda}_{i}^{c}(1+\mu)$ and $f_{i} \leqslant \widehat{f}_{i}$ for all $i$ and thus $A^{c}=\varnothing$ and $A^{\ell}=\{1, \ldots, n\}$. The remaining part of the paper restricts attention to 
this case of a pure reinsurance captive. Using $T\left(\ldots, C_{i}, \ldots,\right)=\left(\sum_{i=1}^{n} C_{i}-D\right)^{+}$, an optimal insurance scheme maximises

$$
\begin{gathered}
W=E\left[B_{0}\left(\sum_{i=1}^{n}\left(k_{i}+K_{i}\right)-\min \left\{\sum_{i=1}^{n} C_{i}\left(I_{i}\left(\tilde{x}_{i}\right)\right), D\right\}-Q\right)\right] \\
+\sum_{i=1}^{n} E\left[B_{i}\left(w_{i}-\tilde{x}_{i}+I_{i}\left(\tilde{x}_{i}\right)-P_{i}-k_{i}\right)\right],
\end{gathered}
$$

with respect to $k_{i}, K_{i}, P_{i}, I_{i}(),. C_{i}() \geqslant$.0 for all $i$ and $D \geqslant 0$ subject to (2), (8), $0 \leqslant C_{i}\left(I_{i}\right) \leqslant I_{i}$ and

$$
Q=(1+\mu) E\left[\left(\sum_{i-1}^{n} C_{i}\left(I_{i}\left(\tilde{x}_{i}\right)\right)-D\right)^{+}\right] .
$$

Proposition 4 An optimal reinsurance captive scheme is defined by $I_{i}^{*} \in$ $(0,+\infty), d_{i}^{1}>d_{i}^{0}>0$ for all $i=1, \ldots, n$ such that

$$
\begin{array}{rlrl}
C_{i}\left(I_{i}\right) & =\min \left\{I_{i},\right. & \left.I_{i}^{*}\right\}, \\
I_{i}\left(x_{i}\right) & =0 & & \text { if } x_{i} \leqslant d_{i}^{0}, \\
\mathrm{~d} I_{i}\left(x_{i}\right) / \mathrm{d} x_{i} & \in(0,1) & & \text { if } d_{i}^{0} \leqslant x_{i} \leqslant d_{i}^{1}+I_{i}^{*}, \\
I_{i}\left(x_{i}\right) & =x_{i}-d_{i}^{1} & & \text { if } x_{i}>d_{i}^{1}+I_{i}^{*} .
\end{array}
$$

Proposition 4 is illustrated with Figure $3 .{ }^{24} I_{i}^{*}$ is an upper limit on cessions by local insurer $i$ to the reinsurance captive and $d_{i}^{0}$ is a deductible for business unit $i$, with partial marginal coverage over $\left[d_{i}^{0}, d_{i}^{1}+I_{i}^{*}\right]$ and full marginal coverage above $d_{i}^{1}+I_{i}^{*}$.

The intuition of Proposition 4 is as follows. Let us look first at the determinants of optimal cessions to the reinsurance captive. For a given retrocession deductible $D$ and for given $I_{j}($.$) for all j$ and $C_{j}($.$) for all j \neq i$, increasing $C_{i}\left(I_{i}\right)$ when $I_{i}$ is in some interval $[a, b]$ leads to larger ceded premiums $K_{i}$ and also to larger costs incurred by the captive either directly when $\sum_{j=1}^{n} C_{j}<D$ or indirectly through an increase in the retroceded premium $Q$. The optimal cession scheme $C_{i}\left(I_{i}\right)=\min \left\{I_{i}, I_{i}^{*}\right\}$ trades off the gains drawn from the ceded premiums and the risk-sharing advantage of an umbrella policy against the increase in the captive risks.

\footnotetext{
${ }^{24}$ For the sake of graphical simplicity, in Figure 3 function $I_{i}\left(x_{i}\right)$ is drawn as if it were piecewise linear, which may not be the case. The same remark applies for $I_{i}\left(x_{i}\right)$ and $C_{i}\left(I_{i}\right)$ in the case of Figure 4.
} 
62

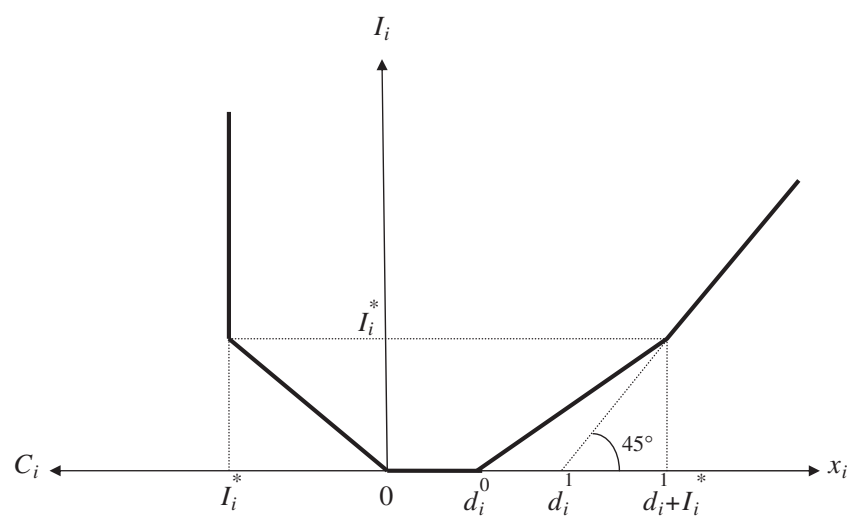

Figure 3. Optimal reinsurance captive scheme.

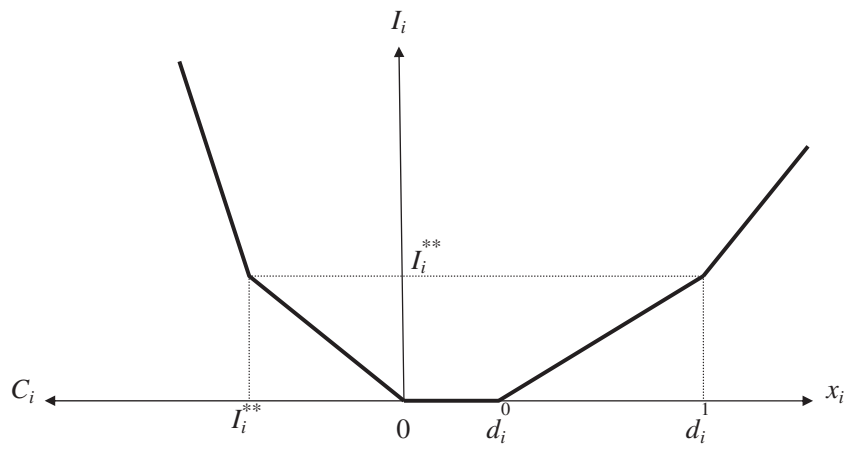

Figure 4. The case of convex capital costs.

A precise definition of the cession upper limit $I_{i}^{*}$ is provided in the proof of Proposition 4 but its intuition is rather straightforward. Let $E\left[B^{\prime}{ }_{0}\left(\Pi_{0}\right)\right]$ be the expected marginal shareholder value of an increase in the captive profit and let $E\left[B_{0}^{\prime}\left(\Pi_{0}\right) \mid C_{i}\right]$ denote this expected marginal value conditionally on the transfer from the captive to local insurer $i$ being equal to $C_{i}{ }^{25}$ The proof of Proposition 4 shows that it is optimal to increase $C_{i}$ when

${ }^{25}$ See the proof of Proposition 3 in the Appendix for explicit definitions of $E\left[B_{0}^{\prime}\left(\Pi_{0}\right)\right]$ and $E\left[B_{0}^{\prime}{ }_{0}\left(\Pi_{0}\right) \mid C_{i}\right]$. In these expressions, expected values are taken with respect to transfers from the captive to all local insurers $j \neq i$ by taking into account the captive's retrocession operations. We have $\partial E\left[B^{\prime}{ }_{0}\left(\Pi_{0}\right) \mid C_{i}\right] / \partial C_{i}>0$ because $B_{0}($.$) is a concave function and an increase in C_{i}$ decreases the captive profit anything else given. 
$E\left[B_{0}^{\prime}\left(\Pi_{0}\right) \mid C_{i}\right]<\left(1+\lambda_{i}^{k}\right) E\left[B_{0}^{\prime}\left(\Pi_{0}\right)\right]$ because in that case, given the local insurer's cost of capital $\lambda_{i}^{k}$, the positive shareholder value of larger recouped premium exceeds the negative shareholder value of larger captive liabilities. It is thus optimal to increase $C_{i}$ as much as possible, and thus to choose $C_{i}\left(I_{i}\right)=I_{i}$, when $I_{i}<I_{i}^{*}$, where $I_{i}^{*}$ is defined by

$$
E\left[B_{0}^{\prime}\left(\Pi_{0}\right) \mid C_{i}=I_{i}^{*}\right]=\left(1+\lambda_{i}^{k}\right) E B_{0}^{\prime}\left(\Pi_{0}\right)
$$

Hence $C_{i}\left(I_{i}\right)=I_{i}$ is optimal when $I_{i} \leqslant I_{i}^{*}$ and the firm should choose $C_{i}\left(I_{i}\right)=I_{i}^{*}$ when $I_{i}>I_{i}^{*}$.

The shape of the optimal cession treaty $C_{i}\left(I_{i}\right)=\min \left\{I_{i}, I_{i}^{*}\right\}$ affects the shape of the insurance coverage provided by the local insurer to the business unit. When $x_{i}$ is not too large, we have $I_{i}\left(x_{i}\right)<I_{i}^{*}$. Then any increase in $I_{i}\left(x_{i}\right)$ is reflected by an equivalent increase in the ceded risks $C_{i}\left(I_{i}\right)$. Hence when $x_{i}$ is increasing, the increase in $I_{i}\left(x_{i}\right)$ should reach an optimal compromise between providing additional coverage to business unit $i$ and not inducing too much additional risks for the captive. This compromise leads to partial coverage "at the margin", that is, a coinsurance mechanism $\mathrm{d} I_{i}\left(x_{i}\right) / \mathrm{d} x_{i} \in(0,1)$. Insurance coverage is triggered only when the loss is larger than the threshold $d_{i}^{0}$ since, as usual, because of transaction costs it is optimal to have zero coverage when losses are very low. When $x_{i}$ is large enough $\left(x_{i} \geqslant d_{i}^{1}+I_{i}^{*}\right)$, we have $I_{i}\left(x_{i}\right) \geqslant I_{i}^{*}$ and then increasing $I_{i}\left(x_{i}\right)$ has no effect on the captive earnings: it is only reflected by an increase in the premium $P_{i}$ paid to the local insurer, without any change in premiums ceded to the captive. In that case, the optimal insurance contract then specifies full coverage at the margin, that is, $I_{i}\left(x_{i}\right)=x_{i}-d_{i}^{1}$ as in standard insurance contract with constant loading.

We have assumed so far that the capital loading is proportional to the expected indemnity cost incurred by local insurers. Although proportional loadings are usual in the literature on optimal insurance contracting, this is not a very satisfactory assumption when corporate insurance demand is at stake, particularly for multinational corporations that may incur large risks, and it may even be regarded as completely unacceptable when the focus is on insurance capital requirements. Indeed the capital costs involved by insurers' risk management and by regulatory constraints may be small or even negligible for small risks that do not affect the solvency of the insurers, while they strongly increase when insurers face large size liabilities. This is more adequately modelled by assuming that capital costs depend on insurers' liabilities in a non-linear way.

Let us now write insurer $i$ 's capital cost as $E\left[Z_{i}\left(I_{i}\left(\tilde{x}_{i}\right)\right)\right]$, where function $Z_{i}($.$) is$ such that $Z^{\prime}{ }_{i}>0$ and $Z^{\prime \prime}{ }_{i}>0$. So far we had $Z_{i}\left(x_{i}\right) \equiv \lambda_{i}^{k} x_{i}$, but now assuming more generally that $Z_{i}$ (.) is a convex function allows us to consider the case where small risks do not involve any significant effect on insurers' required capital, while an increase in the exposure to large risks would result in a large 
64

increase in capital loading. Under this assumption, the premium charged by local insurer $i$ is written as

$$
P_{i}=\left(1+\lambda_{i}^{c}\right) E\left[I_{i}\left(\tilde{x}_{i}\right)\right]+E\left[Z_{i}\left(I_{i}\left(\tilde{x}_{i}\right)\right)\right]+f_{i}
$$

instead of (2).

Eq. (13) reflects the empirical observation that capital requirements increase more than proportionally with the size of the insurer's liabilities, and that the highest loss layers have the strongest effect on the allocation of capital among lines of business. This will be the case if the insurer allocates capital to lines of business based upon their contribution to the total firm's VaR (99\%) loss scenario or if Tail Value at Risk (TVaR) is used as a basis for allocating capital. In such cases, capital is mainly allocated to perils that contribute to the worst scenarios. ${ }^{26}$ Bodoff ${ }^{27}$ describes a formulation of VaR capital that allocates capital to all losses rather than only to extreme losses in the tail of the distribution, but in Bodoff's formulation capital is allocated disproportionately to severe losses. A different approach would consist in assuming that insurance prices are given by the expectation of costs (particularly capital costs) with respect to a distorted probability as in the approach of Wang. ${ }^{28}$ Finally, if the corporate losses that are covered by insurance contracts were correlated with returns in financial markets, then insurance pricing should not only depend on the probability distribution of indemnities as in (13), but also on the state in which these losses occur as in weighted pricing functionals such as the conditional tail expectation and the Esscher premium. ${ }^{29}$ We here keep the simplifying assumption that the risk exposures of business units are mutually independent and without correlation with the state of financial markets.

The premiums which are ceded by local insurer $i$ to the reinsurance captive include the decrease in the capital cost, which goes down from $E\left[Z_{i}\left(I_{i}\left(\tilde{x}_{i}\right)\right)\right]$ to $E\left[Z_{i}\left(I_{i}\left(\tilde{x}_{i}\right)-C_{i}\left(I_{i}\left(\tilde{x}_{i}\right)\right)\right)\right]$ when the local insurer's risk exposure goes down from $I_{i}\left(\tilde{x}_{i}\right)$ to $I_{i}\left(\tilde{x}_{i}\right)-C_{i}\left(I_{i}\left(\tilde{x}_{i}\right)\right)$. We thus have

$$
K_{i}=E\left[C_{i}\left(I_{i}\left(\tilde{x}_{i}\right)\right)\right]+E\left[Z_{i}\left(I_{i}\left(\tilde{x}_{i}\right)\right)\right]-E\left[Z_{i}\left(I_{i}\left(\tilde{x}_{i}\right)-C_{i}\left(I_{i}\left(\tilde{x}_{i}\right)\right)\right)\right],
$$

instead of (8).

Proposition 5 Assume that the local insurer's cost of capital is $E\left[Z_{i}\left(I_{i}\left(\tilde{x}_{i}\right)\right)\right]$ with $Z^{\prime}{ }_{i}>0$ and $Z^{\prime \prime}{ }_{i}>0$. Then an optimal insurance scheme is characterised by

\footnotetext{
${ }^{26}$ See Kreps (2005) and Venter (2006).

${ }^{27}$ Bodoff (2009).

${ }^{28}$ Wang $(1996,2000)$.

${ }^{29}$ See Furman and Zitikis (2009).
} 
$I_{i}^{* *} \in(0,+\infty), d_{i}^{1}>d_{i}^{0}>0$ for all $i=1, \ldots, n$ such that

$$
\begin{aligned}
C_{i}\left(I_{i}\right) & =I_{i} & & \text { if } I_{i} \leqslant I_{i}^{* *}, \\
\frac{\mathrm{d} C_{i}}{\mathrm{~d} I_{i}} & \in(0,1) & & \text { if } I_{i}>I_{i}^{* *}, \\
I_{i}\left(x_{i}\right) & =0 & & \text { if } x_{i} \leqslant d_{i}^{0}, \\
\mathrm{~d} I_{i}\left(x_{i}\right) / \mathrm{d} x_{i} & \in(0,1) & & \text { if } x_{i}>d_{i}^{0},
\end{aligned}
$$

with $I_{i}\left(d_{i}^{1}\right)=I_{i}^{* *}$ and $I_{i+}^{\prime}\left(d_{i}^{1}\right)>I_{i-}^{\prime}\left(d_{i}^{1}\right){ }^{30}$

Proposition 5 is illustrated with Figure 4. Assuming that the marginal cost of capital is increasing provides a different picture of the optimal cession mechanism. Now the equality between expected costs and expected benefits of an increase in ceded premiums is written as

$$
E\left[B_{0}^{\prime}\left(\Pi_{0}\right) \mid C_{i}\right]=\left[1+Z_{i}^{\prime}\left(I_{i}-C_{i}\right)\right] E\left[B_{0}^{\prime}\left(\Pi_{0}\right)\right],
$$

where the variable marginal cost of capital $Z_{i}^{\prime}\left(I_{i}-C_{i}\right)$ has been substituted to $\lambda_{i}^{k}$. There exists an upper limit on indemnities $I_{i}^{* *}$ given by

$$
E\left[B_{0}^{\prime}\left(\Pi_{0}\right) \mid C_{i}=I_{i}^{* *}\right]=\left[1+Z_{i}^{\prime}(0)\right] E\left[B_{0}^{\prime}\left(\Pi_{0}\right)\right]
$$

such that the risk is fully ceded to the reinsurance captive when $I_{i}$ is lower than $I_{i}^{* *}$, but there are partial cessions "at the margin" when $I_{i}$ exceeds $I_{i}^{* *}$. As in the case of constant marginal cost of capital, the optimal cession scheme $C_{i}\left(I_{i}\right)$ results from the trade-off between on one side the gain drawn both from the ceded premiums and from the better risk sharing provided by an umbrella policy and on the other side the increase in the captive costs. When $I_{i}<I_{i}^{* * *}$ the balance tips in favour of increasing the cession even with the smallest capital marginal costs $Z_{i}^{\prime}(0)$ ceded to the captive and in that case $C_{i}\left(I_{i}\right)=I_{i}$ is optimal. When $I_{i}>I_{i}^{* * *}$, it is optimal to increase the cession $C_{i}\left(I_{i}\right)$ up to the level where the expected gain in the firm's marginal value $\left[1+Z_{i}^{\prime}\left(I_{i}-C_{i}\right)\right] E\left[B^{\prime}{ }_{0}\left(\Pi_{0}\right)\right]$ derived from ceded premiums matches the expected loss due to larger indemnity payment $E\left[B^{\prime}{ }_{0}\left(\prod_{0}\right) \mid C_{i}\right]$, hence a marginal cession rate

$$
\frac{\mathrm{d} C_{i}}{\mathrm{~d} I_{i}}=\frac{\alpha Z_{i}^{\prime \prime}\left(I_{i}-C_{i}\right)}{\alpha Z_{i}^{\prime \prime}\left(I_{i}-C_{i}\right)+\frac{\partial E\left[B_{0}^{\prime} \mid C_{i}\right]}{\partial C_{i}}} \in(0,1),
$$

where $\alpha=E\left[B^{\prime}{ }_{0}\left(\Pi_{0}\right)\right]$. The optimal indemnity schedule involves partial insurance at the margin $\mathrm{d} I_{i}\left(x_{i}\right) / \mathrm{d} x_{i} \in(0,1)$ because an increase in coverage either involves

\footnotetext{
${ }^{30} I_{i+}^{\prime}\left(d_{i}^{1}\right)$ and $I_{i-}^{\prime}\left(d_{i}^{1}\right)$ respectively denote the right-sided and left-sided derivatives of $I_{i}\left(x_{i}\right)$ in $d_{i}{ }^{1}$.
} 
an equivalent increase in the risks incurred by the captive when $I_{i}\left(x_{i}\right)<I_{i}^{* * *}$ and also an increase in the local insurer's cost of capital which is only partially recouped through premium cessions when $I_{i}\left(x_{i}\right)>I_{i}^{* * *}$.

\section{Numerical simulations}

Let us present numerical examples derived from a simplified version of the model. We start with the case of an insurance captive analysed in Section "Optimal insurance captive schemes". Consider a symmetric version of our model, with $n$ identical business units: $n_{c}$ units are insured by the captive and $n_{\ell}=n-n_{c}$ units purchase insurance from local insurers. We thus assume $A^{l} \cap A^{c}=\varnothing$ because of fixed underwriting costs. For each business unit, an accident occurs with probability $p$, and in that case the loss $x$ is uniformly distributed over an interval $[0, \bar{x}]$. We also assume $B_{i}\left(\Pi_{i}\right)=\ln \left(\Pi_{i}\right)$ for all $i=0,1, \ldots, n$. Let $\lambda^{c}, \widehat{\lambda}^{c}, \lambda^{k}, f, \widehat{f}, P$ be respectively the claims handling costs, the capital cost, the fixed underwriting cost and the premium charged by local insurers. $w_{1}$ denotes the initial endowment of a business unit and $k_{c}$ (respect. $k_{\ell}$ ) denotes the transfer to the captive from any business unit that is insured (respect. not insured) by the captive. Finally, $\mu$ and $D$ still denote the reinsurance loading and deductible. In all our derivations we assume $n=10$, $p=0.1, \bar{x}=0.5, f=\widehat{f}_{c}=0.005$. $^{31}$

When $X_{1}, \ldots, X_{n}$ are i.i.d. random variables with the same distribution as $X$, we write $X^{* n} \equiv \sum_{i=1}^{n} X_{i}$. Eqs. (2), (3) and (5) are then rewritten as

$$
\begin{aligned}
P= & \left(1+\lambda^{c}+\lambda^{k}\right) \times E[I(\tilde{x})]+f, \\
Q= & (1+\mu) \times E\left[\left(\left(1+\widehat{\lambda}^{c}\right) \times(t(\tilde{x}))^{* n_{c}}-D\right)^{+}\right], \\
W= & E\left[\ln \left(n_{c} k_{c}+\left(n-n_{c}\right) k_{\ell}-n_{c} \widehat{f}_{c}-Q-\min \left\{D,\left(1+\widehat{\lambda}^{c}\right) \times[t(\tilde{x})]^{* n_{c}}\right\}\right)\right] \\
& +n_{c} E\left[\ln \left(w_{1}-\tilde{x}+t(\tilde{x})-k_{c}\right)\right]+n_{\ell} E\left[\ln \left(w_{1}-\tilde{x}+I(\tilde{x})-P-k_{\ell}\right)\right],
\end{aligned}
$$

where $I(x)$ and $t(x)$ are the indemnity schedules respectively offered by local insurers and by the captive, with $I(x)=\left(x-d^{0}\right)^{+}$. For the sake of computational simplicity, we restrict attention to piecewise linear indemnity schedules offered by the captive and we thus write $t(x)=a\left(x-d^{1}\right)^{+}$, with $0<a<1$. $W$ is maximised with respect to $n_{c} \in\{0,1, \ldots, 10\}, k_{c}, k_{\ell}, d^{0}, d^{1}, a, D$ subject to the constraints that define $P$ and $Q$.

\footnotetext{
${ }^{31}$ Assumption $f=\widehat{f}_{c}=0.005$ guarantees that it is optimal to purchase insurance either from the captive or from a local insurer but not from both sources simultaneously.
} 
Table 1 Some numerical derivations for optimal insurance captive schemes

\begin{tabular}{|c|c|c|c|c|c|c|c|c|c|c|c|}
\hline \multicolumn{4}{|c|}{ Parameters } & \multicolumn{8}{|c|}{ Variables } \\
\hline$\lambda^{k}$ & $\lambda^{c}, \widehat{\lambda}^{c}$ & $\mu$ & $w_{1}$ & $n_{c}$ & $d^{0}$ & $k_{\ell}$ & $d^{1}$ & $a$ & $k_{c}$ & $D$ & $R R R H(\%)$ \\
\hline 0.03 & 0.05 & 0.05 & 1 & 0 & 0.07 & 0.088 & - & - & - & - & 26 \\
\hline 0.04 & 0.05 & 0.05 & 1 & 0 & 0.08 & 0.088 & - & - & - & - & 29.4 \\
\hline$\geqslant 0.045$ & 0.05 & 0.05 & 1 & 10 & - & - & 0.06 & 0.90 & 0.112 & 0.10 & 49 \\
\hline 0.03 & 0.1 & 0.05 & 1 & 0 & 0.11 & 0.088 & - & - & - & - & 39.2 \\
\hline 0.04 & 0.1 & 0.05 & 1 & 0 & 0.12 & 0.088 & - & - & - & - & 42.2 \\
\hline$\geqslant 0.047$ & 0.1 & 0.05 & 1 & 10 & - & - & 0.11 & 0.92 & 0.109 & 0.09 & 56.9 \\
\hline 0.03 & 0.05 & 0.1 & 1 & 0 & 0.07 & 0.088 & - & - & - & - & 26 \\
\hline 0.04 & 0.05 & 0.1 & 1 & 0 & 0.08 & 0.088 & - & - & - & - & 29.4 \\
\hline$\geqslant 0.075$ & 0.05 & 0.1 & 1 & 10 & - & - & 0.09 & 0.88 & 0.110 & 0.17 & 70.8 \\
\hline 0.03 & 0.05 & 0.05 & 2 & 0 & 0.15 & 0.179 & - & - & - & - & 51 \\
\hline$\geqslant 0.036$ & 0.05 & 0.05 & 2 & 10 & - & - & 0.13 & 0.81 & 0.196 & 0.16 & 81.4 \\
\hline
\end{tabular}

Table 1 allows us to visualise the effects of changes in cost parameters and wealth on the optimal insurance captive scheme. ${ }^{32} R R R H$ denotes the Risk Retention Rate measured at the Holding level. Results show that an all or nothing solution is optimal, that is, all business units should purchase insurance from the captive or none of them should do it. When $\lambda^{c}=\hat{\lambda}^{c}$, we know from Proposition 1 that a sufficient condition for purchasing insurance from the captive to be optimal is (approximately) $\lambda^{k}>\mu$. When $\lambda^{k}<\mu$, the optimal scheme trades off the advantages of an umbrella policy offered by the captive against the lower costs of local insurers. In these examples, the captive dominates local insurers for values of the capital cost that are lower than the reinsurance loading. For instance, when $\lambda^{c}=\hat{\lambda}^{c}=\mu=0.05$ and $w_{1}=1$, transferring risks to the captive and reinsuring them with deductible $D=0.10$ is more advantageous than purchasing insurance from local insurers even if their cost

\footnotetext{
32 The value of each business unit and the insurance premiums has a closed form in our setting. This is not the case neither for the reinsurance premium nor for the value of the captive because of the intricate distribution of the cumulated costs transferred to the insurance captive. We derived these values by numerical integration and solved the program with a heuristic algorithm. In this algorithm, units were $10^{-3}$ for $k_{c}$ and $k_{\ell}$ and $10^{-2}$ for the other variables. Computational difficulties were mainly about the risk transferred to the captive, because of the convolution law $[t(\tilde{x})]^{* n_{c}}$. Note that the optimal solution obtained for $n_{c}=n$ does not depend on the cost of capital $\lambda^{k}$. Such a solution was compared with the optimal solution obtained for $n_{c}=0$, which depends on $\lambda^{k}$. Dominant interior solutions with respect to $n_{c} \in(0, n)$ were not found.
} 
of capital loading is only $\lambda^{k}=0.045$ (and a fortiori if it is larger). The local insurer solution dominates the captive solution when $\lambda^{k} \leqslant 0.04$ and there is a jump in $R R R H$ from 29.4 per cent to 49.0 per cent when self-insurance through the captive becomes optimal after a small increase in the cost of capital from 0.04 to 0.045 . Increases in claims handling costs $\lambda^{c}$ and $\hat{\lambda}^{c}$ lead to larger deductibles either by local insurers or by the captive, which is in line with standard results in optimal insurance contract theory ${ }^{33}$ : for instance if $\mu=0.05$, $w_{1}=1$ and $\lambda^{c}$ and $\hat{\lambda}^{c}$ increase from 0.05 to 0.1 , then $d^{0}$ increases from 0.07 to 0.11 if $\lambda^{k}=0.03$ and $d^{1}$ increases from 0.06 to 0.11 if $\lambda^{k} \geqslant 0.047$.

Table 1 also illustrates the consequences of an increase in the reinsurance loading factor. Consider the case where $\lambda^{k} \geqslant 0.075, \lambda^{c}=\widehat{\lambda}^{c}=0.05, w_{1}=1$ : if $\mu$ increases from 0.05 to 0.1 , then $D$ increases from 0.10 to 0.17 , which is the standard direct effect of an increase in the reinsurance loading, and simultaneously $d^{1}$ increases from 0.06 to 0.09 and $a$ lowers from 0.90 to 0.88 , which is an induced effect: higher reinsurance costs lead the captive to provide less complete insurance coverage to business units. Finally, increasing the business units' initial endowments leads to more retention within the captive and the business units, because the $\ln ($.$) function entails the same kind of wealth effect as$ the decreasing absolute risk aversion of standard expected utility theory. For instance, when $\lambda^{c}=\hat{\lambda}^{c}=\mu=0.05$, if $w_{1}$ increases from 1 to 2 , then $D$ increases from 0.10 to $0.16, d^{1}$ increases from 0.06 to 0.13 and $a$ decreases from 0.90 to 0.81 if the business units purchase insurance from the captive, while $d^{0}$ increases from 0.07 or 0.08 to 0.15 if insurance is obtained from local insurers, with an important increase in the retention rate in both cases.

In short, some important features of an optimal insurance captive scheme emerge from these numerical results. Firstly, because of the umbrella policy mechanism, using a captive may be profitable to the firm even if reinsurance costs exceed savings on direct insurance capital cost. Conversely, for given reinsurance costs, if the local insurers' capital cost is low enough (which is likely to be the case in periods of soft insurance markets with large insurers' surplus), then the firm may turn to local insurers and keep its captive dormant, even if it means reinvigorating the captive later, under more favourable market conditions. Secondly, changes in reinsurance loading lead to more or less risk cessions by the captive to reinsurers, and indirectly to more or less retentions in business units. Since capital costs and reinsurance rates do not move in a perfectly synchronised way, there are arbitrage opportunities, which also explains the structural instability in the activity of the captive industry. Thirdly,

\footnotetext{
${ }^{33}$ The consequences of an increase in the loading factor on the optimal level of insurance coverage may be analysed by distinguishing a substitution effect and an income effect, as in the classical theory of consumer demand; see Schlesinger (2000).
} 
Table 2 Some numerical examples for optimal reinsurance captive schemes: The case of a constant marginal cost of capital

\begin{tabular}{lccc|ccccc|c}
\hline \multicolumn{9}{c}{ Parameters } \\
\hline$\lambda^{k}$ & $\lambda^{c}$ & $\mu$ & $w_{1}$ & $d^{0}$ & $a$ & $I^{*}$ & $k$ & $D$ & RRRH(\%) \\
\hline 0.03 & 0.05 & 0.05 & 1 & 0.07 & 0.92 & 0.04 & 0.088 & 0.07 & 38.2 \\
0.04 & 0.05 & 0.05 & 1 & 0.07 & 0.87 & 0.07 & 0.088 & 0.09 & 46.4 \\
0.05 & 0.05 & 0.05 & 1 & 0.06 & 0.77 & 0.07 & 0.088 & 0.09 & 46.4 \\
\hline 0.03 & 0.1 & 0.05 & 1 & 0.11 & 0.93 & 0.04 & 0.088 & 0.07 & 50.2 \\
0.04 & 0.1 & 0.05 & 1 & 0.11 & 0.87 & 0.06 & 0.088 & 0.08 & 55.8 \\
0.05 & 0.1 & 0.05 & 1 & 0.11 & 0.88 & 0.12 & 0.088 & 0.09 & 61.6 \\
\hline 0.03 & 0.05 & 0.1 & 1 & 0.07 & 0.94 & 0.03 & 0.088 & 0.10 & 36 \\
0.04 & 0.05 & 0.1 & 1 & 0.08 & 0.99 & 0.04 & 0.088 & 0.11 & 42 \\
0.05 & 0.05 & 0.1 & 1 & 0.09 & 1 & 0.05 & 0.088 & 0.12 & 47.7 \\
\hline 0.03 & 0.05 & 0.05 & 2 & 0.12 & 0.73 & 0.07 & 0.179 & 0.13 & 65.6 \\
0.04 & 0.05 & 0.05 & 2 & 0.11 & 0.69 & 0.12 & 0.179 & 0.15 & 76.1 \\
0.05 & 0.05 & 0.05 & 2 & 0.10 & 0.68 & 0.16 & 0.179 & 0.16 & 81.7 \\
\hline
\end{tabular}

because of a wealth effect the larger the firm's initial endowment, the larger the risk retention in the captive and in the business units, which reinforces the price effect argument for the variability in the captive activity. When changes in price or wealth parameters make the use of the captive profitable, there is a jump in the risk retention rate of the holding company, which illustrates the role of captives as expansion tanks for the parent's self-insurance capacity.

The results of the previous section can also be illustrated by examples derived from the same basic assumptions: 10 symmetric business units, $B_{i}\left(\Pi_{i}\right)=\ln \left(\Pi_{i}\right)$ for all $i$, and each business unit facing the risk of an accident with probability $p=0.1$, with losses $\tilde{x}$ uniformly distributed over $[0, \bar{x}]$ and $\bar{x}=0.5$. We restrict attention to piecewise linear indemnity schedules. In the case of a constant marginal cost of capital (Proposition 4), we thus assume that $I^{\prime}(x)$ is constant and equal to $a \in(0,1)$ when $x \in\left[d^{0}, d^{1}+I^{*}\right]^{34}$

Increasing cessions to the captive trades off the advantages of an umbrella policy obtained through the captive stop-loss reinsurance policy against the costs of the captive's liabilities. Table 2 confirms that ceteris paribus (i.e. for given values of $\lambda^{c}, \mu$ and $w_{1}$ ), the higher $\lambda^{k}$, the higher $I^{*}$ because a higher capital cost makes risk cessions more profitable. We also observe that increasing $\mu$ from 0.05

\footnotetext{
${ }^{34}$ As in the previous simulations, we assume $f=0.005$ and $w_{0}=0$.
} 
Table 3 Some numerical examples for optimal reinsurance captive schemes: The case of a convex cost of capital

\begin{tabular}{lccc|ccccccc|c}
\hline \multicolumn{10}{c}{ Parameters } \\
\hline$\lambda^{k}$ & $\lambda^{c}$ & $\mu$ & $w_{1}$ & $d^{0}$ & $a$ & $b$ & $I^{* *}$ & $c$ & $k$ & $D$ & $R R R H(\%)$ \\
\hline 0.03 & 0.05 & 0.05 & 1 & 0.07 & 0.93 & 0.95 & 0.05 & 0.25 & 0.088 & 0.09 & 48.7 \\
0.04 & 0.05 & 0.05 & 1 & 0.07 & 0.85 & 0.97 & 0.06 & 0.58 & 0.088 & 0.10 & 52.3 \\
0.05 & 0.05 & 0.05 & 1 & 0.07 & 0.88 & 0.99 & 0.12 & 0.99 & 0.088 & 0.10 & 52.8 \\
\hline 0.03 & 0.1 & 0.05 & 1 & 0.11 & 0.93 & 0.95 & 0.05 & 0.19 & 0.088 & 0.08 & 57.9 \\
0.04 & 0.1 & 0.05 & 1 & 0.11 & 0.85 & 0.97 & 0.06 & 0.55 & 0.088 & 0.09 & 61 \\
0.05 & 0.1 & 0.05 & 1 & 0.10 & 0.82 & 0.99 & 0.11 & 0.99 & 0.088 & 0.09 & 61.1 \\
\hline 0.03 & 0.05 & 0.1 & 1 & 0.08 & 0.97 & 0.98 & 0.04 & 0.06 & 0.088 & 0.12 & 46.8 \\
0.04 & 0.05 & 0.1 & 1 & 0.08 & 0.94 & 0.95 & 0.05 & 0.09 & 0.088 & 0.13 & 52 \\
0.05 & 0.05 & 0.1 & 1 & 0.06 & 0.70 & 0.93 & 0.06 & 0.10 & 0.088 & 0.14 & 56.5 \\
\hline 0.03 & 0.05 & 0.05 & 2 & 0.10 & 0.65 & 0.91 & 0.09 & 0.20 & 0.179 & 0.15 & 75.6 \\
0.04 & 0.05 & 0.05 & 2 & 0.11 & 0.71 & 0.89 & 0.12 & 0.32 & 0.179 & 0.16 & 80.8 \\
0.05 & 0.05 & 0.05 & 2 & 0.11 & 0.72 & 0.99 & 0.17 & 0.99 & 0.179 & 0.16 & 81.9 \\
\hline
\end{tabular}

to 0.1 (with $\lambda^{k}=0.03,0.04$ or $0.05, \lambda^{c}=0.05$ and $w_{1}=1$ ) leads to higher values for $D$, once again this is the direct effect of a higher reinsurance loading, but it also leads to lower values for $I^{*}$ because of an induced effect of the cost of retrocessions on optimal cessions. The effects of changes of $\lambda^{c}$ and $w_{1}$ are as expected: when $\lambda^{k}=0.03,0.04$ or 0.05 , increasing $\lambda^{c}$ from 0.05 to 0.1 and keeping $\mu=0.05$ and $w_{1}=1$ or increasing $w_{1}$ from 1 to 2 and keeping $\lambda^{c}=\mu=0.05$ leads to larger $d^{0}$ : these are standard price and wealth effects associated with changes in the loading factor or initial endowment.

The case of a convex cost of capital is illustrated by assuming $Z(I)=$ $\lambda^{k} I+0.05 I^{2}, I^{\prime}(x)=a$ if $x \in\left[d^{0}, d^{1}\right]$ and $I^{\prime}(x)=b$ if $x>d^{1}$ (or equivalently if $\left.I(x)>I^{* *}\right)$ with $0<a<b<1$. The marginal cession rate is denoted as $C^{\prime}(I)=c$, with $0<c<1$ when $I>I^{* * *}$. The results are in Table 3 , with expected effects of parameter changes. In particular, an increase in the capital cost parameter $\lambda^{k}$ stimulates the risk cessions to the captive by increasing both $I^{* *}$ and $c$.

\section{Conclusion}

This paper has focused attention on the role of insurance and reinsurance captives as optimal risk-sharing arrangements for large corporations with decentralised business units. Several conclusions emerge from this analysis. Firstly, reinsurance captives dominate insurance captives when standard direct 
insurers have lower claims handling and underwriting costs than captives: indeed, through a reinsurance captive the holding company may cumulate the benefits drawn from the lower costs of the fronters and the risk-sharing optimality of an umbrella policy offered by retrocessionnaires. Secondly, the optimal insurance scheme of decentralised business units involves deductible insurance contracts with partial coverage at the margin (at least when losses are in some interval) when business units are insured either directly by an insurance captive or through a fronter that cedes its risks to a reinsurance captive. Thirdly, when local insurers act as fronters, they fully cede their risks to the reinsurance captive up to a certain limit. Partial cessions above this limit are optimal under increasing marginal cost of capital. The reinsurance captive retrocedes its risk to the reinsurance market through a stop-loss contract, thereby offering an umbrella insurance policy to the holding company. Fourthly, the optimal insurance coverage as well as the optimal cession and retrocession operations depend on price parameters, and particularly on the capital cost of local insurers and on the loading factor of retrocessionnaires, as well as on initial endowments of the business units. Variations across time of these cost and wealth parameters affect the attractiveness of captive arrangements and may result in fluctuations in the activity of the captive industry.

These conclusions have been reached in a very stylised model that generates observed contractual risk-sharing arrangements as optimal contracts in the line of Raviv. ${ }^{35}$ However, that has been done by reducing all market imperfections to financial costs of contracting and by deliberately neglecting several important features of the captive industry. Fronters could simultaneously cede risks to the reinsurance captive and to other reinsurers, but contractual arrangements between the corporation and a fronter usually prevent the latter from doing so. If all local insurers belong to the same insurance group (say, a large direct insurer with worldwide activities), then this insurance group may cede its risks to a global reinsurer whose risk could be retroceded through an umbrella policy. However, as mentioned in the introduction of this paper, there are many reasons for which managing the ceded risks in a reinsurance captive is usually more efficient (besides the fact that all local insurers may not be subsidiaries of the same insurance group with coordinated risk cessions). In particular, the efficiency gains drawn from more flexibility in intertemporal capital allocation is one of the most important reasons why offshore captive reinsurance mechanisms cannot be easily imitated by global reinsurers. Furthermore, insurance and reinsurance captives are frequently part and parcel of an integrated risk management strategy of the parent company, for which a non-dedicated reinsurance structure may be less efficient in terms of

\footnotetext{
${ }^{35}$ Raviv (1979).
} 
incentives and information. Captives may indeed have access to cheaper information about business units than independent insurers. They can be used to promote more efficient risk prevention by centralising information about accident or liability risks of the business units, and by helping the parent company to form objective beliefs about some of the risks faced by individual business units. Tax effects have been left out although they have been at the origin of the captive industry and they still interfere with the optimisation of captive insurance arrangements. Finally, going deeper into the analysis of the wealth and price effects would require a dynamic multiperiod model of the captives' activity. These are important research avenues for better understanding the optimal insurance strategies of large corporations.

\section{Acknowledgement}

We are grateful to Carole Bernard, two referees and participants in seminars at Ecole Polytechnique and Vienna (EGRIE annual meeting) for useful comments and suggestions.

\section{References}

A.M. Best (2009) European Captives - A Growth Market during a Challenging Time, Best's Special Report, Market Review, 27 July.

Banks, E. (2004) Alternative Risk Transfer. Integrated Risk Management through Insurance, Reinsurance and the Capital Markets, Wiley Finance Series, Chichester, UK: Wiley.

Bodoff, N.M. (2009) 'Capital allocation by percentile layer', Variance 3(1): 13-30.

Cross, M., Davidson, W. and Thornton, J. (1988) 'Taxes, stock returns and captive insurance subsidiaries', Journal of Risk and Insurance 55(2): 331-338.

Cummins, J.D. and Doherty, N.A. (2002) 'Capitalization of the property-liability insurance industry: Overview', Journal of Financial Services Research 21(1-2): 5-14.

Diallo, A. and Kim, S. (1989) 'Asymmetric information, captive insurer's formation, and manager's welfare gain', Journal of Risk and Insurance 56(2): 233-251.

Froot, K.A. (2007) 'Risk management, capital budgeting, and capital structure policy for insurers and reinsurers', Journal of Risk and Insurance 74(2): 273-299.

Froot, K.A., Scharfstein, D. and Stein, J. (1993) 'Risk management: Coordinating corporate investment and financing policies', Journal of Finance 48(5): 1629-1658.

Froot, K.A. and Stein, D.S. (1998) 'Risk management, capital budgeting and capital structure policy for financial institutions: An integrated approach', Journal of Financial Economics 47(1): 55-82.

Furman, E. and Zitikis, R. (2009) 'Weighted pricing functionals with applications to insurance: An overview', North American Actuarial Journal 13(4): 483-496.

Gollier, C. (2000) 'Optimal insurance design: What can we do with and without expected utility?', in G. Dionne (ed.) Handbook of Insurance, Dordrecht, MA: Kluwer, pp. 97-116.

Han, L.-M. and Lai, G. (1991) 'The tax deductibility of premiums paid to captive insurers: A risk reduction approach', Journal of Risk and Insurance 58(1): 47-62. 
Hartzell, J.C., Titman, S. and Twite, G. (2006) 'Why do firms hold so much cash? A tax-based explanation', mimeo.

Kreps, R. (2005) 'Riskiness leverage models', Proceedings of the Casualty Actuarial Society 92: $31-60$.

Lai, G. and Witt, R. (1995) 'The tax deductibility of captive insurance premiums: An assessment and alternative perspective', Journal of Risk and Insurance 62(2): 230-252.

Meier, U. and Outreville, F. (2006) 'Business cycles in insurance and reinsurance: The case of France, Germany and Switzerland', Journal of Risk Finance 7(2): 160-176.

Meltzer, A.H. (1963) 'The demand for money: A cross-section study of business firms', Quarterly Journal of Economics 77(3): 405-422.

Miller, M.H. and Orr, D. (1966) 'A model of demand for money by firms', Quarterly Journal of Economics 80(3): 413-435.

Mulligan, C.B. (1997) 'Scale economies, the value of time and the demand for money: Longitudinal evidence from firms', Journal of Political Economy 105(5): 1061-1079.

Picard, P. and Pinquet, J. (2011) 'Optimal risk financing in large corporations through insurance captives’, Ecole Polytechnique, Department of Economics, Cahier N²011-02.

Raviv, A. (1979) 'The design of an optimal insurance policy', American Economic Review 69(1): 84-96.

Schlesinger, H. (2000) 'The theory of insurance demand', in G. Dionne (ed.) Handbook of Insurance, Dordrecht, MA: Kluwer, pp. 131-151.

Scordis, N.A., Barrese, J. and Yokoyama, M. (2007) 'Conditions for captive insurer value: A Monte Carlo simulation', Journal of Insurance Issues 30(2): 79-101.

Scordis, N. and Porat, M. (1998) 'Captive insurance companies and manager-owner conflicts', Journal of Risk and Insurance 65(2): 289-302.

Smith, B. (1986) 'Analyzing the tax deductibility of premiums paid to captive insurers', Journal of Risk and Insurance 53(1): 85-103.

Tirole, J. (2006) The Theory of Corporate Finance, Princeton, NJ: Princeton University Press.

Venter, G.G. (2006) 'Adapting banking models to insurer ERM', ERM Symposium.

Wang, S.S. (1996) 'Premium calculation by transforming the layer premium density', ASTIN Bulletin 26(1): 71-92.

Wang, S.S. (2000) 'A class of distortion operators for pricing financial and insurance risks', Journal of Risk and Insurance 67(1): 15-36.

Weiss, M. and Chung, J.-H. (2004) 'US reinsurance prices, financial quality, and global capacity', Journal of Risk and Insurance 71(3): 437-467.

\section{Appendix}

\section{Proof of Proposition 1}

Let $\mathcal{P}^{0}=\left\{I_{i}^{0}\left(x_{i}\right), P_{i}^{0}, t_{i}^{0}\left(x_{i}\right), k_{i}^{0}\right.$ for $\left.i=1, \ldots, n ; T^{0}\left(t_{1}, \ldots, t_{n}\right), Q^{0}\right\}$ a feasible insurance captive scheme. Let $C_{0}$ (resp. $C_{1}$ ) be the set of business units such that $(1+\mu)\left(1+\widehat{\lambda}_{i}^{c}\right) \leqslant 1+\lambda_{i}$ and $\widehat{f}_{i} \leqslant f_{i}$ and that are insured (resp. not insured) by the captive under $\mathcal{P}^{0}$. Let $C_{2}$ be the set of other units, with $C_{0} \cup C_{1} \cup C_{2}=\{1, \ldots, n\}$. Consider another feasible scheme $\mathcal{P}^{1}=$ $\left\{I_{i}^{1}\left(x_{i}\right), \quad P_{i}^{1}, \quad t_{i}^{1}\left(x_{i}\right), \quad k_{i}^{1}\right.$ for $\left.i=1, \ldots, n ; \quad T^{1}\left(t_{1}, \ldots, t_{n}\right), \quad Q^{1}\right\}, \quad$ with $I_{i}^{1}\left(x_{i}\right) \equiv 0$, $P_{i}^{1}=0, t_{i}^{1}\left(x_{i}\right) \equiv t_{i}^{0}\left(x_{i}\right)+I_{i}^{0}\left(x_{i}\right), k_{i}^{1}=k_{i}^{0}+P_{i}^{0}$ if $i \in C_{0} \cup C_{1}$ and $I_{i}^{1}\left(x_{i}\right) \equiv I_{i}^{0}\left(x_{i}\right), P_{i}^{1}=P_{i}^{0}$, 
74

$t_{i}^{1}\left(x_{i}\right) \equiv t_{i}^{0}\left(x_{i}\right), k_{i}^{1}=k_{i}^{0}$ if $i \in C_{2}$. Let $\Pi_{i}^{0}\left(x_{i}\right)$ and $\Pi_{i}^{1}\left(x_{i}\right)$ be the current cash flows of business unit $i$ respectively under $\mathcal{P}^{0}$ and $\mathcal{P}^{1}$ as a function of losses $x_{i}$. We obviously have $\Pi_{i}^{0}\left(x_{i}\right) \equiv \Pi_{i}^{1}\left(x_{i}\right)$ from (1). Let for all $i$

$$
\gamma_{i}\left(r_{i}\right)=\frac{I_{i}^{0}\left(x_{i}\right)}{I_{i}^{0}\left(x_{i}\right)+t_{i}^{0}\left(x_{i}\right)} \in[0,1] \text { if } I_{i}^{0}\left(x_{i}\right)+t_{i}^{0}\left(x_{i}\right)=r_{i}>0 .
$$

Since $I_{i}^{0}\left(x_{i}\right)$ and $t_{i}^{0}\left(x_{i}\right)$ are non-decreasing, $\gamma_{i}\left(r_{i}\right)$ is well defined for all $r_{i}>0$. Let

$$
T^{1}\left(t_{1}, \ldots, t_{n}\right) \equiv T^{0}\left(\ldots,\left(1-\gamma_{i}\left(t_{i}\right)\right) t_{i}, \ldots\right)+\sum_{i \in C_{0} \cup C_{1}}\left(1+\hat{\lambda}_{i}^{c}\right) \gamma_{i}\left(t_{i}\right) t_{i}
$$

Using (3) and (A.1) gives

$$
\begin{aligned}
Q^{1}= & (1+\mu) E\left[T^{1}\left(\ldots, t_{i}^{1}\left(\tilde{x}_{i}\right), \ldots\right)\right] \\
= & (1+\mu) E\left[T^{0}\left(\ldots,\left(1-\gamma_{i}\left(t_{i}^{1}\left(\tilde{x}_{i}\right)\right)\right) t_{i}^{1}\left(\tilde{x}_{i}\right), \ldots,\right)\right] \\
& +(1+\mu) E \sum_{i \in C_{0} \cup C_{1}}\left(1+\hat{\lambda}_{i}^{c}\right) \gamma_{i}\left(t_{i}^{1}\left(\tilde{x}_{i}\right)\right) t_{i}^{1}\left(\tilde{x}_{i}\right) .
\end{aligned}
$$

Using (3) and $\left(1-\gamma_{i}\left(t_{i}^{1}\left(x_{i}\right)\right)\right) t_{i}^{1}\left(x_{i}\right) \equiv t_{i}^{0}\left(x_{i}\right)$ and $\left.\gamma_{i}\left(t_{i}^{1}\left(x_{i}\right)\right)\right) t_{i}^{1}\left(x_{i}\right) \equiv I_{i}^{0}\left(x_{i}\right)$ for all $i$ yields

$$
\begin{aligned}
Q^{1} & =Q^{0}+(1+\mu) E \sum_{i \in C_{0} \cup C_{1}}\left(1+\hat{\lambda}_{i}^{c}\right) I_{i}^{0}\left(\tilde{x}_{i}\right) \leqslant Q^{0}+\sum_{i \in C_{0} \cup C_{1}}\left(1+\lambda_{i}\right) E I_{i}^{0}\left(\tilde{x}_{i}\right) \\
& =Q^{0}+\sum_{i \in C_{0}^{\prime} \cup C_{1}}\left(P_{i}^{0}-f_{i}\right)
\end{aligned}
$$

where $C_{0}^{\prime} \subset C_{0}$ refers to the set of business units that belongs to $C_{0}$ and that are simultaneously insured by the captive and the local insurer in $\mathcal{P}^{0} .{ }^{36}$ Let $\Pi_{0}^{0}\left(x_{1}, \ldots, x_{n}\right)$ and $\Pi_{0}^{1}\left(x_{1}, \ldots, x_{n}\right)$ be the profit of the captive respectively under $\mathcal{P}^{0}$ and $\mathcal{P}^{1}$. Let $C_{2}^{\prime}$ be the subset of $C_{2}$ that gathers the units of $C_{2}$ that are insured by the captive (and also possibly by local insurers). Under $\mathcal{P}^{1}$ the

\footnotetext{
${ }^{36}$ Note that $I_{i}^{0}\left(x_{i}\right) \equiv 0$ if $i \in C_{0} \backslash C_{0}^{\prime}$.
} 
captive provides insurance to the business units in $C_{0} \cup C_{1} \cup C_{2}^{\prime}$. Hence using (4), (A.1) and (A.2) gives

$$
\begin{aligned}
\Pi_{0}^{1}\left(x_{1}, \ldots, x_{n}\right)= & \sum_{i=1}^{n} k_{i}^{1}-\sum_{i \in C_{0} \cup C_{1} \cup C_{2}^{\prime}}\left[\left(1+\widehat{\lambda}_{i}^{c}\right) t_{i}^{1}\left(x_{i}\right)+\widehat{f}_{i}\right]+T^{1}\left(\ldots, t_{i}^{1}\left(x_{i}\right), \ldots\right)-Q^{1} \\
& \geqslant \sum_{i=1}^{n} k_{i}^{1}-\sum_{i \in C_{0} \cup C_{1} \cup C_{2}^{\prime}}\left[\left(1+\widehat{\lambda}_{i}^{c}\right) t_{i}^{1}\left(x_{i}\right)+\widehat{f}_{i}\right]+T^{0}\left(\ldots,\left(1-\gamma_{i}\left(t_{i}^{1}\left(x_{i}\right)\right)\right) t_{i}^{1}\left(x_{i}\right), \ldots\right) \\
& +\sum_{i \in C_{0} \cup C_{1}}\left(1+\widehat{\lambda}_{i}^{c}\right) \gamma_{i}\left(t_{i}^{1}\left(x_{i}\right)\right) t_{i}^{1}\left(x_{i}\right)-Q^{0}-\sum_{i \in C_{0}^{\prime} \cup C_{1}}\left(P_{i}^{0}-f_{i}\right) .
\end{aligned}
$$

Using firstly $\left(1-\gamma_{i}\left(t_{i}^{1}\left(x_{i}\right)\right)\right) t_{i}^{1}\left(x_{i}\right) \equiv t_{i}^{0}\left(x_{i}\right)$ for all $i$, secondly $k_{i}^{1}=k_{i}^{0}+P_{i}^{0}$ if $i \in C_{0} \cup C_{1}$ with $P_{i}^{0}=0$ if $i \notin C^{\prime}{ }_{0}$ and $k_{i}^{1}=k_{i}^{0}$ if $i \in C_{2}$, thirdly $t_{i}^{0}\left(x_{i}\right) \equiv 0$ if $i \in C_{1}$ and fourthly $t_{i}^{1}\left(x_{i}\right)=t_{i}^{0}\left(x_{i}\right)$ if $i \in C_{2}^{\prime}$ then gives

$$
\begin{aligned}
\Pi_{0}^{1}\left(x_{1}, \ldots, x_{n}\right) \geqslant & \sum_{i=1}^{n} k_{i}^{0}-\sum_{i \in C_{0} \cup C_{1} \cup C_{2}^{\prime}} \widehat{f}_{i}+\sum_{i \in C_{0}^{\prime} \cup C_{1}} P_{i}^{0}+T^{0}\left(\ldots, t_{i}^{0}\left(x_{i}\right), \ldots\right) \\
& -\sum_{i \in C_{0} \cup C_{2}^{\prime}}\left(1+\widehat{\lambda}_{i}^{c}\right) t_{i}^{0}\left(x_{i}\right)-Q^{0}-\sum_{i \in C_{0}^{\prime} \cup C_{1}}\left(P_{i}^{0}-f_{i}\right) \\
= & \sum_{i=1}^{n} k_{i}^{0}-\sum_{i \in C_{0} \cup C_{2}^{\prime}}\left[\left(1+\widehat{\lambda}_{i}^{c}\right) t_{i}^{0}\left(x_{i}\right)+\widehat{f}_{i}\right]+T^{0}\left(\ldots, t_{i}^{0}\left(x_{i}\right), \ldots\right)-Q^{0} \\
& +\sum_{i \in C_{1}}\left(f_{i}-\widehat{f}_{i}\right)+\sum_{i \in C_{0}^{\prime}} f_{i} \\
= & \Pi_{0}^{0}\left(x_{1}, \ldots, x_{n}\right)+\sum_{i \in C_{1}}\left(f_{i}-\widehat{f}_{i}\right)+\sum_{i \in C_{0}^{\prime}} f_{i} \geqslant \Pi_{0}^{0}\left(x_{1}, \ldots, x_{n}\right) .
\end{aligned}
$$

Hence $\mathcal{P}^{1}$ weakly dominates $\mathcal{P}^{0}$ (it provides the same profit to each business units and no lower profit to the captive in all states of the world). $\mathcal{P}^{1}$ strongly dominates $\mathcal{P}^{0}$ if $C_{0}^{\prime} \neq \varnothing$ or if $f_{i}>\widehat{f}_{i}$ for at least one $i$ in $C_{1}$.

Given $\left\{I_{i}(),. P_{i}, t_{i}(),. k_{i}\right.$ for all $\left.i=1, \ldots, n\right\}$ the optimal reinsurance policy $\{T($.$) ,$ $Q$ \} maximises $E B_{0}\left(\Pi_{0}\right)$, where $\Pi_{0}$ is given by (4), subject to (3). Using the concavity of $B_{0}($.$) and the Umbrella Policy Theorem { }^{37}$ shows that $T($.$) is a$ function of the aggregate loss of the captive $\sum_{i}\left(1+\widehat{\lambda}_{i}^{c}\right) t_{i}\left(x_{i}\right)$. Using $\mu>0$ and a standard result in optimal insurance contract theory then yields $T\left(t_{1}, \ldots, t_{n}\right) \equiv\left[\sum_{i}\left(1+\widehat{\lambda}_{i}^{c}\right) t_{i}-D\right]^{+}$, with $D>0$.

\section{Proof of Proposition 2}

Consider a given index $i \in\{1, \ldots, n\}$. Let $\tilde{y}_{i}=\sum_{j \neq i}\left(1+\widehat{\lambda}_{j}^{c}\right) t_{j}\left(\tilde{x}_{j}\right)$ and let $F_{i}\left(y_{i}\right)$ be the cumulative distribution function of $\tilde{y}_{i}$ over $\mathbb{R}$, with $F_{i}(0)=0$ and $F_{i}\left(\bar{y}_{i}\right)=1$,

\footnotetext{
${ }^{37}$ (see Gollier, 2000).
} 
where $\bar{y}_{i}=\sum_{j \neq i}\left(1+\hat{\lambda}_{j}^{c}\right) t_{j}\left(\bar{x}_{j}\right)$. Choosing $k_{j}, I_{j}($.$) and t_{j}($.$) optimally for all j \neq i$, and thus for an optimal distribution $F_{i}\left(y_{i}\right)$, the optimal insurance captive scheme maximises

$$
\begin{aligned}
& \int_{0}^{\bar{x}_{i}} \int_{-\infty}^{D-\left(1+\widehat{\lambda}_{i}^{c} t_{i}\left(x_{i}\right)\right.} B_{0}\left(\sum_{j=1}^{n} k_{j}-y_{i}-\left(1+\widehat{\lambda}_{i}^{c}\right) t_{i}\left(x_{i}\right)-\sum_{j \in A^{c}} \widehat{f}_{j}-Q\right) \mathrm{d} F_{i}\left(y_{i}\right) \mathrm{d} \Phi\left(x_{i}\right) \\
& +\int_{0}^{\bar{x}_{i}}\left[1-F_{i}\left(D-\left(1+\widehat{\lambda}_{i}^{c}\right) t_{i}\left(x_{i}\right)\right)\right] B_{0}\left(\sum_{j=1}^{n} k_{j}-D-\sum_{j=A^{c}} \widehat{f}_{i}-Q\right) \mathrm{d} \Phi\left(x_{i}\right) \\
& +\int_{0}^{\bar{x}_{i}} B_{i}\left(w_{i}-x_{i}+I_{i}\left(x_{i}\right)-P_{i}+t_{i}\left(x_{i}\right)-k_{i}\right) \mathrm{d} \Phi_{i}\left(x_{i}\right),
\end{aligned}
$$

with respect to $D, Q, k_{i}, P_{i}$ and $I_{i}(),. t_{i}() \geqslant$.0 , subject to

$$
\begin{gathered}
P_{i}=\left(1+\lambda_{i}^{c}+\lambda_{i}^{k}\right) \int_{0}^{\bar{x}_{i}} I_{i}\left(x_{i}\right) \mathrm{d} \Phi\left(x_{i}\right)+f_{i} \quad \text { if } i \in A^{\ell}, \\
P_{i}=0 \quad \text { if } i \notin A^{\ell}, \\
Q=(1+\mu) \int_{0}^{\bar{x}_{i}}\left(\int_{D-\left(1+\widehat{\lambda}_{i}^{c}\right) t_{i}\left(x_{i}\right)}^{\bar{y}_{i}}\left(y_{i}+\left(1+\widehat{\lambda}_{i}^{c}\right) t_{i}\left(x_{i}\right)-D\right) \mathrm{d} F_{i}\left(y_{i}\right)\right) \mathrm{d} \Phi\left(x_{i}\right) .
\end{gathered}
$$

Let $\alpha$ and $\beta$ be Lagrange multipliers associated with (A.3) and (A.5) respectively and let

$$
\begin{aligned}
E B_{0}^{\prime} \equiv & \left.\int_{0}^{\bar{x}_{i}} \int_{-\infty}^{D-\left(1+\widehat{\lambda}_{i}^{c}\right) t_{i}\left(x_{i}\right)} B_{0}^{\prime}\left(\sum_{j=1}^{n} k_{j}-y_{i}-\left(1+\widehat{\lambda}_{i}^{c}\right) t_{i}\left(x_{i}\right)-\sum_{j \in A^{c}} \widehat{f}_{j}-Q\right)\right) \mathrm{d} F_{i}\left(y_{i}\right) \mathrm{d} \Phi\left(x_{i}\right) \\
& +\int_{0}^{\bar{x}_{i}}\left[1-F_{i}\left(D-\left(1+\widehat{\lambda}_{i}^{c}\right) t_{i}\left(x_{i}\right)\right)\right] B_{0}^{\prime}\left(\sum_{j=1}^{n} k_{j}-D-\sum_{j \in A^{c}} \widehat{f}_{j}-Q\right) \mathrm{d} \Phi\left(x_{i}\right), \\
E B_{i}^{\prime} \equiv & \int_{0}^{\bar{x}_{i}} B_{i}\left(w_{i}-x_{i}+I_{i}\left(x_{i}\right)-P_{i}+t_{i}\left(x_{i}\right)-k_{i}\right) \mathrm{d} \Phi_{i}\left(x_{i}\right) .
\end{aligned}
$$


The first-order optimality conditions on $P_{i}$ and $I_{i}($.$) respectively give E B_{i}^{\prime}=\alpha$ and

$$
B_{i}^{\prime}\left(w_{i}-x_{i}+I_{i}\left(x_{i}\right)-P_{i}-k_{i}\right)-\alpha\left(1+\lambda_{i}^{c}+\lambda_{i}^{k}\right) \leqslant 0,=0 \text { if } I_{i}\left(x_{i}\right)>0
$$

if $i \in A^{\ell}$ (and thus $i \notin A^{c}$ ), which yields $I_{i}\left(x_{i}\right)=\left(x_{i}-d_{i}^{0}\right)^{+}$, with $d_{1}^{0}>0$. The optimality conditions associated with $k_{i}, Q, D, t_{i}($.) respectively give

$$
\begin{gathered}
E B_{i}^{\prime}=E B_{0}^{\prime}, \\
E B_{0}^{\prime}=\beta, \\
\beta(1+\mu)=B_{0}^{\prime}\left(\sum_{j=1}^{n} k_{j}-D-\sum_{j \in A^{c}} \widehat{f_{i}}-Q\right), \\
B_{i}^{\prime}\left(w_{i}-x_{i}+t_{i}\left(x_{i}\right)-k_{i}\right)-\left(1+\widehat{\lambda}_{i}^{c}\right) E\left[B_{0}^{\prime} \mid t_{i}\left(x_{i}\right)\right] \leqslant 0,=0 \text { if } t_{i}\left(x_{i}\right)>0,
\end{gathered}
$$

for $i \in A^{c}$ (and thus $i \notin A^{\ell}$ ) where

$$
\begin{aligned}
E\left[B_{0}^{\prime} \mid t\right] \equiv & \int_{-\infty}^{D-\left(1+\widehat{\lambda}_{i}\right) t} B_{0}^{\prime}\left(\sum_{j=1}^{n} k_{j}-y_{i}-\left(1+\widehat{\lambda}_{i}^{c}\right) t-\sum_{j \in A^{c}} \widehat{f}_{j}-Q\right) \mathrm{d} F_{i}\left(y_{i}\right) \\
& +\left[1-F_{i}\left(D-\left(1+\widehat{\lambda}_{i}^{c}\right) t\right)\right] B_{0}^{\prime}\left(\sum_{j=1}^{n} k_{j}-D-\sum_{j \in A^{c}} \widehat{f}_{i}-Q\right)
\end{aligned}
$$

and

$$
\frac{\partial E\left[B_{0}^{\prime} \mid t\right]}{\partial t}=-\left(1+\widehat{\lambda}_{i}^{c}\right) \int_{-\infty}^{D-\left(1+\widehat{\lambda}_{i}^{c}\right) t} B_{0}^{\prime \prime}\left(\sum_{j=1}^{n} k_{j}-y_{i}-\sum_{j \in A^{c}} \widehat{f}_{j}-Q\right) \mathrm{d} F_{i}\left(y_{i}\right)>0 .
$$

Differentiating (A.10) gives

$$
\frac{\mathrm{d} t_{i}}{\mathrm{~d} x_{i}}=\frac{{B^{\prime \prime}}_{i}\left(w_{i}-x_{i}+t_{i}\left(x_{i}\right)-k_{i}\right)}{B_{i}^{\prime \prime}\left(w_{i}-x_{i}+t_{i}\left(x_{i}\right)-k_{i}\right)-\left.\left(1+\widehat{\lambda}_{i}\right) \frac{\partial E\left[B_{0}^{\prime} \mid t\right]}{\partial t}\right|_{t=t_{i}\left(x_{i}\right)}},
$$


and thus $\mathrm{d} t_{i} / \mathrm{d} x_{i} \in(0,1)$ if $t_{i}\left(x_{i}\right)>0$. (A.10) implies $t_{i}\left(x_{i}\right)=0$ if $x_{i} \in\left[0-d_{i}^{1}\right]$ and $t_{i}\left(x_{i}\right)>0$ if $x_{i}>d_{i}^{1}$ where $d_{i}^{1}$ is such that $B_{i}^{\prime}\left(w_{i}-d_{i}^{1}-k_{i}\right)=\left(1+\hat{\lambda}_{i}^{c}\right) E\left[B^{\prime}{ }_{0} \mid 0\right]$. Suppose $d_{i}^{1}<0$. (A.10) would then give

$$
\begin{aligned}
E B_{i}^{\prime} & =\int_{0}^{\bar{x}_{i}} B_{i}^{\prime}\left(w_{i}-x_{i}+t_{i}\left(x_{i}\right)-k_{i}\right) \mathrm{d} \Phi_{i}\left(x_{i}\right)=\left(1+\widehat{\lambda}_{i}^{c}\right) \int_{0}^{\bar{x}_{i}} E\left[B_{0}^{\prime} \mid t_{i}\left(x_{i}\right)\right] \mathrm{d} \Phi_{i}\left(x_{i}\right) \\
& =\left(1+\hat{\lambda}_{i}^{c}\right) E B_{0}^{\prime}>E B_{0}^{\prime},
\end{aligned}
$$

hence a contradiction with (A.7).

Proof of Proposition 3

Let $\mathcal{P}^{0}=\left\{I_{i}^{0}\left(x_{i}\right), P_{i}^{0}, t_{i}^{0}\left(x_{i}\right), k_{i}^{0}, C_{i}^{0}\left(I_{i}\right), K_{i}^{0} ; T^{0}\left(\ldots, t_{i}, \ldots ; \ldots, C_{i}, \ldots\right), Q^{0}\right\}_{i=1, \ldots, n}$ a feasible insurance-reinsurance captive scheme. Let $C_{0}$ (resp. $C_{1}$ ) be the set of business units such that $\lambda_{i}^{c} \leqslant \hat{\lambda}_{i}^{c}(1+\mu)$ and $f_{i} \leqslant \widehat{f}_{i}$ and that are directly insured only by the captive (resp. directly coinsured by the local insurer and the captive) under $\mathcal{P}^{0}$. Let $C_{2}$ be the set of other business units, with $C_{0} \cup C_{1} \cup C_{2}=\{1, \ldots, n\}$. Let

$\gamma_{i}\left(r_{i}\right)=I_{i}^{0}\left(x_{i}\right) /\left[I_{i}^{0}\left(x_{i}\right)+t_{i}^{0}\left(x_{i}\right)\right] \in[0,1] \quad$ if $I_{i}^{0}\left(x_{i}\right)+t_{i}^{0}\left(x_{i}\right)=r_{i}>0 \quad$ if $i \in C_{0} \cup C_{1}$, $\gamma_{i}\left(r_{i}\right) \equiv 1$ if $i \in C_{2}$.

Consider another insurance scheme $\mathcal{P}^{1}=\left\{I_{i}^{1}\left(x_{i}\right), P_{i}^{1}, t_{i}^{1}\left(x_{i}\right), k_{i}^{1}, C_{i}^{1}\left(I_{i}\right), K_{i}^{1}\right.$; $\left.T^{1}\left(\ldots, t_{i}, \ldots ; \ldots, C_{i}, \ldots\right), Q^{1}\right\}_{i=1, \ldots, n}$ such that

$$
\begin{aligned}
I_{i}^{1}\left(x_{i}\right) & \equiv I_{i}^{0}\left(x_{i}\right)+t_{i}^{0}\left(x_{i}\right) \quad \text { if } i \in C_{0} \cup C_{1}, \\
C_{i}^{1}\left(I_{i}\right) & \equiv C_{i}^{0}\left(\gamma_{i}\left(I_{i}\right) I_{i}\right)+\left(1-\gamma_{i}\left(I_{i}\right)\right) I_{i} \quad \text { if } i \in C_{0} \cup C_{1}, \\
k_{i}^{1} & \equiv k_{i}^{0}-\left(1+\lambda_{i}\right) E t_{i}^{0}\left(\tilde{x}_{i}\right)-f_{i} \quad \text { if } i \in C_{0}, \\
k_{i}^{1} & \equiv k_{i}^{0}-\left(1+\lambda_{i}\right) E t_{i}^{0}\left(\tilde{x}_{i}\right) \quad \text { if } i \in C_{1}, \\
I_{i}^{1}\left(x_{i}\right) & \equiv I_{i}^{0}\left(x_{i}\right), C_{i}^{1}\left(I_{i}\right) \equiv C_{i}^{0}\left(I_{i}\right), t_{i}^{1}\left(x_{i}\right) \equiv t_{i}^{0}\left(x_{i}\right), k_{i}^{1}=k_{i}^{0} \quad \text { if } i \in C_{2},
\end{aligned}
$$

with $P_{i}^{1}$ given by (2) for all $i$ and $Q^{1}$ given by (3). Since $P_{i}^{1}+k_{i}^{1}=P_{i}^{0}+k_{i}^{0}$ and $I_{i}^{1}\left(x_{i}\right)+t_{i}^{1}\left(x_{i}\right) \equiv I_{i}^{0}\left(x_{i}\right)+t_{i}^{0}\left(x_{i}\right)$, we have $\Pi_{i}^{1}\left(x_{i}\right) \equiv \Pi_{i}^{0}\left(x_{i}\right)$ for all $i$ where $\Pi_{i}^{0}\left(x_{i}\right)$ and $\Pi_{i}^{1}\left(x_{i}\right)$ respectively denote the current cash flows of business unit $i$ under $\mathcal{P}^{0}$ and $\mathcal{P}^{1}$ as functions of losses $x_{i}$. Let also

$$
T^{1}\left(\ldots, t_{i}, \ldots ; \ldots, C_{i}, \ldots\right)=T^{0}\left(\ldots, t_{i}^{\prime}, \ldots, C_{i}^{\prime}, \ldots\right)-\sum_{i \in C_{0} \cup C_{1}} \hat{\lambda}_{i} t_{i}^{\prime}
$$


where

$$
\begin{aligned}
& t_{i}^{\prime}=\left(1-\gamma_{i}\left(I_{i}\right)\right) I_{i} \text { and } C_{i}^{\prime}=C_{i}^{0}\left(\gamma_{i}\left(I_{i}\right) I_{i}\right) \text { with } I_{i}=\left(C_{i}^{1}\right)^{-1}\left(C_{i}\right) \text { if } \in C_{0} \cup C_{1}, \\
& t_{i}^{\prime}=t_{i} \text { and } C_{i}^{\prime}=C_{i} \text { if } i \in C_{2} .
\end{aligned}
$$

For all $i \in C_{0} \cup C_{1}$, when direct insurer $i$ pays indemnity $I_{i}$ to business unit $i$ and receives $C_{i}^{1}\left(I_{i}\right)$ from the captive under $\mathcal{P}^{1}$, the captive pays $t^{\prime}=\left(1-\gamma_{i}\left(I_{i}\right)\right) I_{i}$ to business unit $i$ and direct insurer $i$ receives $C_{i}^{\prime}=C_{i}^{0}\left(\gamma_{i}\left(I_{i}\right) I_{i}\right)$ from the captive under $\mathcal{P}^{0}$. We thus have

$$
Q^{0}=(1+\mu) E T^{0}\left(\ldots, t_{i}^{\prime}, \ldots ; \ldots C_{i}^{\prime}, \ldots\right)
$$

Consequently,

$$
\begin{aligned}
Q^{1} & =(1+\mu) E T^{1}\left(\ldots, t_{i}^{1}\left(\tilde{x}_{i}\right), \ldots ; \ldots, C_{i}\left(I_{i}\left(\tilde{x}_{i}\right)\right), \ldots\right) \\
& =Q^{0}-(1+\mu) \sum_{i \in C_{0} \cup C_{1}} \widehat{\lambda}_{i} E t_{i}^{0}\left(x_{i}\right) .
\end{aligned}
$$

Let $C_{2}^{\prime}$ be the subset of $C_{2}$ that gathers the units of $C_{2}$ that are directly insured by the captive (and also possibly by local insurers). Under $\mathcal{P}^{1}$ only the business units of $C_{2}^{\prime}$ are directly insured by the captive. Let $\Pi_{0}^{0}\left(x_{1}, \ldots, x_{n}\right)$ and $\Pi_{0}^{1}\left(x_{1}, \ldots, x_{n}\right)$ be the profit of the captive respectively under $\mathcal{P}^{0}$ and $\mathcal{P}^{1}$. We have

$$
\begin{aligned}
\Pi_{0}^{1}\left(x_{1}, \ldots, x_{n}\right)= & \sum_{i=1}^{n} k_{i}^{1}-\sum_{i \in C_{2}^{\prime}}\left[\left(1+\widehat{\lambda}_{i}^{c}\right) t_{i}^{1}\left(x_{i}\right)+\widehat{f}_{i}\right]+\sum_{i=1}^{n}\left[K_{i}^{1}-C_{i}\left(I_{i}^{1}\left(x_{i}\right)\right)\right] \\
& +T^{1}\left(\ldots, t_{i}^{1}\left(x_{i}\right), \ldots, C_{i}^{1}\left(I_{i}^{1}\left(x_{i}\right)\right), \ldots,\right)-Q^{1} \\
= & \sum_{i=1}^{n} k_{i}^{1}-\sum_{i \in C_{2}^{\prime}}\left[\left(1+\widehat{\lambda}_{i}^{c}\right) t_{i}^{1}\left(x_{i}\right)+\widehat{f}_{i}\right]+\sum_{i=1}^{n}\left[K_{i}^{0}-C_{i}\left(I_{i}^{0}\left(x_{i}\right)\right)\right] \\
& +\sum_{i \in C_{o} \cup C_{1}}\left[\left(1+\lambda_{i}^{k}\right) E t_{i}^{0}\left(\tilde{x}_{i}\right)-t_{i}^{0}\left(x_{i}\right)\right] \\
& +T^{1}\left(\ldots, t_{i}^{1}\left(x_{i}\right), \ldots, C_{i}^{1}\left(I_{i}^{1}\left(x_{i}\right)\right) \ldots,\right)-Q^{1} .
\end{aligned}
$$

Using (A.12), (A.13) and

$$
\sum_{i=1}^{n} k_{i}^{1}=\sum_{i=1} k_{i}^{0}-\sum_{i \in C_{0} \cup C_{1}}\left(1+\lambda_{i}\right) E t_{i}^{0}\left(\tilde{x}_{i}\right)-\sum_{i \in C_{0}} f_{i}
$$


80

gives

$$
\begin{aligned}
\Pi_{0}^{1}\left(x_{1}, \ldots, x_{n}\right)= & \sum_{i=1}^{n} k_{i}^{0}-\sum_{i \in C_{0} \cup C_{1} \cup C_{2}^{\prime}}\left[\left(1+\widehat{\lambda}_{i}^{c}\right) t_{i}^{0}\left(x_{i}\right)+\widehat{f}_{i}\right]+\sum_{i=1}^{n}\left[K_{i}^{0}-C_{i}\left(I_{i}^{0}\left(x_{i}\right)\right)\right] \\
& +T^{0}\left(\ldots, t_{i}^{0}\left(x_{i}\right), \ldots, C_{i}^{0}\left(I_{i}^{0}\left(x_{i}\right)\right) \ldots,\right)-Q^{0} \\
& +\sum_{i \in C_{0} \cup C_{1}}\left[\widehat{\lambda}_{i}^{c}(1+\mu)-\lambda_{i}^{c}\right] E t_{i}^{0}\left(\tilde{x}_{i}\right)+\sum_{i \in C_{0}}\left(\widehat{f}_{i}-f_{i}\right)+\sum_{i \in C_{1}} f_{i} \\
= & \Pi_{0}^{1}\left(x_{1}, \ldots, x_{n}\right)+\sum_{i \in C_{0} \cup C_{1}}\left[\widehat{\lambda}_{i}^{c}(1+\mu)-\lambda_{i}^{c}\right] E t_{i}^{0}\left(\tilde{x}_{i}\right) \\
& +\sum_{i \in C_{0}}\left(\widehat{f}_{i}-f_{i}\right)+\sum_{i \in C_{1}} f_{i} \geqslant \Pi_{0}^{1}\left(x_{1}, \ldots, x_{n}\right) .
\end{aligned}
$$

Hence in an optimal insurance scheme, any business unit $i$ such that $\lambda_{i}^{c} \leqslant \widehat{\lambda}_{i}^{c}(1+\mu)$ and $f_{i} \leqslant \widehat{f}_{i}$ should be directly insured by the local insurer only, possibly with reinsurance by the captive.

Given the transfer schedules $t_{i}\left(x_{i}\right)$ and $C_{i}\left(I_{i}\right)$ the captive bears a total random cost $\sum_{i=1}^{n}\left[\left(1+\widehat{\lambda}_{i}^{c}\right) t_{i}\left(x_{i}\right)+C_{i}\left(I_{i}\left(x_{i}\right)\right)\right]$. The umbrella policy theorem then shows that the optimal reinsurance contract of the captive specifies a transfer schedule $T$, which depends on this total loss, and using $\mu>0$ a standard result in insurance contract theory shows that it is a straight deductible contract.

\section{Proof of Proposition 4}

Part 1

We first characterise functions $C_{i}\left(I_{i}\right)$. Consider a given index $i \in\{1, \ldots, n\}$. Let

$$
\tilde{z}_{i} \equiv \sum_{j \neq i} C_{j}\left(I_{j}\left(\tilde{x}_{j}\right)\right)
$$

and let $G_{i}\left(z_{i}\right)$ be the cumulative distribution function of $\tilde{z}_{i}$ over $\mathbb{R}$, with $G_{i}(0)=0$ and $G_{i}\left(\tilde{z}_{i}\right)=1$, where $\tilde{z}_{i}=\sum_{j \neq i} C_{i}\left(I_{j}\left(\bar{x}_{j}\right)\right)$. Let $\Gamma_{i}\left(I_{i}\right)$ be the cumulative distribution function of $\tilde{I}_{i} \equiv I_{i}\left(\tilde{x}_{i}\right)$ over $\left[0, \bar{I}_{i}\right]$,with $\bar{I}_{i}=I_{i}\left(\bar{x}_{i}\right)$. For $K_{j}, C_{j}($.$) chosen optimally for$ all $j \neq i$ and $k_{j}, I_{j}($.$) chosen optimally for all j$, and thus for optimal induced distributions $G_{i}\left(z_{i}\right)$ and $\Gamma_{i}\left(I_{i}\right)$, the optimal insurance scheme maximises

$$
\begin{aligned}
& \int_{0}^{\bar{I}_{i}}\left\{\int_{-\infty}^{\left.D-C_{i}\left(I_{i}\right)\right)} B_{0}\left(\sum_{j=1}^{n}\left(k_{j}+K_{j}\right)-z_{i}-C_{i}\left(I_{i}\right)\right)-Q\right) \mathrm{d} G_{i}\left(z_{i}\right) \\
& \left.\quad+\left[1-G_{i}\left(D-C_{i}\left(I_{i}\right)\right)\right] B_{0}\left(\sum_{j=1}^{n}\left(k_{j}+K_{j}\right)-D-Q\right)\right\} \mathrm{d} \Gamma_{i}\left(I_{i}\right)
\end{aligned}
$$


with respect to $Q, D, K_{i}, C_{i}($.$) subject to$

$$
\begin{gathered}
K_{i}=\left(1+\lambda_{i}^{k}\right) \int_{0}^{\bar{I}_{i}} C_{i}\left(I_{i}\right) \mathrm{d} \Gamma_{i}\left(I_{i}\right), \\
Q=(1+\mu) \int_{0}^{\bar{I}_{i}}\left[\int_{D-C_{i}\left(I_{i}\right)}^{\bar{y}_{i}}\left(z_{i}+C_{i}\left(I_{i}\right)-D\right) \mathrm{d} G_{i}\left(z_{i}\right)\right] \mathrm{d} \Gamma_{i}\left(I_{i}\right), \\
0 \leqslant C_{i}\left(I_{i}\right) \leqslant I_{i} \quad \text { for all } I_{\mathrm{i}} \in\left[0, \bar{I}_{i}\right] .
\end{gathered}
$$

Let $\alpha$ and $\beta$ be Lagrange multipliers respectively associated with (A.14) and (A.15). The first-order optimality conditions associated with $K_{i}$ and $Q$ are written as

where

$$
E B_{0}^{\prime}=\alpha=\beta
$$

$$
\begin{aligned}
E B_{0}^{\prime} & \equiv \int_{0}^{\bar{I}_{i}}\left\{\int_{-\infty}^{\left.D-C_{i}\left(I_{i}\right)\right)} B_{0}^{\prime}\left(\sum_{j=1}^{n}\left(k_{j}+K_{j}\right)-z_{i}-C_{i}\left(I_{i}\right)\right)-Q\right) \mathrm{d} G_{i}\left(z_{i}\right) \\
& \left.\left.+\left[1+G_{i}\left(D-C_{i}\left(I_{i}\right)\right)\right] B_{0}^{\prime}\left(\sum_{j=1}^{n}\left(k_{j}+K_{j}\right)-D-Q\right)\right)\right\} \mathrm{d} \Gamma_{i}\left(I_{i}\right) .
\end{aligned}
$$

The first-order optimality conditions associated with $D$ and $C_{i}($.$) yield$

$$
\beta(1+\mu)=B_{0}^{\prime}\left(\sum_{j=1}^{n}\left(k_{j}+K_{j}\right)-D-Q\right),
$$

and

$$
\alpha\left(1+\lambda_{i}^{k}\right)-E\left[B_{0}^{\prime} \mid C_{i}\left(I_{i}\right)\right] \geqslant 0,=0 \quad \text { if } C_{i}\left(I_{i}\right)<I_{i},
$$

where

$$
\begin{aligned}
E\left[B_{0}^{\prime} \mid C\right] \equiv & \int_{-\infty}^{D-C} B_{0}^{\prime}\left(\sum_{j=1}^{n}\left(k_{j}+K_{j}\right)-z_{i}-C-Q\right) \mathrm{d} G_{i}\left(z_{i}\right) \\
& +\left[1-G_{i}(D-C)\right] B_{0}^{\prime}\left(\sum_{j=1}^{n}\left(k_{j}+K_{j}\right)-D-Q\right) .
\end{aligned}
$$


We have

$$
\frac{\partial E\left[B_{0}^{\prime} \mid C\right]}{\partial C}=-\int_{-\infty}^{D-C} B_{0}^{\prime \prime}\left(\sum_{j=1}^{n}\left(k_{j}+K_{j}\right)-z_{i}-C-Q\right) \mathrm{d} G_{i}\left(z_{i}\right)>0
$$

Hence from (A.19), we have $C_{i}\left(I_{i}\right)=I_{i}$ if $I_{i} \leqslant I_{i}^{*}$ and $C_{i}\left(I_{i}\right)=I_{i}^{*}$ if $I_{i}>I_{i}^{*}$, where $I_{i}^{*}$ is given by $\alpha\left(1+\lambda_{i}^{k}\right)-E\left[B^{\prime}{ }_{0} \mid I_{i}^{*}\right]=0$.

\section{Part 2}

We now characterise functions $I_{i}\left(x_{i}\right)$. We know that there exists $I_{i}^{*}$ such that $C_{i}\left(I_{i}\right)=\min \left\{I_{i}, I_{i}^{*}\right\}$. Choosing optimally $k_{j}, K_{j}, I_{j}($.$) for all j \neq i$ and $C_{j}($.$) for all j$, and thus for an optimal distribution $G_{i}\left(z_{i}\right)$ the optimal insurance scheme maximises

$$
\begin{aligned}
& \int_{0}^{\bar{x}_{i}} \int_{-\infty}^{D-C_{i}\left(I_{i}\left(x_{i}\right)\right)} B_{0}\left(\sum_{j=1}^{n}\left(k_{j}+K_{j}\right)-z_{i}-C_{i}\left(I_{i}\left(x_{i}\right)\right)-Q\right) \mathrm{d} G_{i}\left(z_{i}\right) \mathrm{d} \Phi_{i}\left(x_{i}\right) \\
& +\int_{0}^{\bar{x}_{i}}\left[1-G_{i}\left(D-C_{i}\left(I_{i}\left(x_{i}\right)\right)\right)\right] B_{0}\left(\sum_{j=1}^{n}\left(k_{j}+K_{j}\right)-D-Q\right) \mathrm{d} \Phi_{i}\left(x_{i}\right) \\
& +\int_{0}^{\bar{x}_{i}} B_{i}\left(w_{i}-x_{i}+I_{i}\left(x_{i}\right)-P_{i}-k_{i}\right) \mathrm{d} \Phi_{i}\left(x_{i}\right)
\end{aligned}
$$

with respect to $D, Q, k_{i}, K_{i}, P_{i}, I_{i}() \geqslant$.0 , subject to

$$
\begin{gathered}
K_{i}=\left(1+\lambda_{i}^{k}\right) \int_{0}^{\bar{x}_{i}} C_{i}\left(I_{i}\left(x_{i}\right)\right) \mathrm{d} \Phi_{i}\left(x_{i}\right), \\
Q=(1+\mu) \int_{0}^{\bar{x}_{i}}\left(\int_{D-C_{i}\left(I_{i}\left(x_{i}\right)\right)}^{\bar{y}_{i}}\left(z_{i}+C_{i}\left(I_{i}\left(x_{i}\right)\right)-D\right) \mathrm{d} G_{i}\left(z_{i}\right)\right) \mathrm{d} \Phi\left(x_{i}\right), \\
P_{i}=\left(1+\lambda_{i}^{c}+\lambda_{i}^{k}\right) \int_{0}^{\bar{x}_{i}} I_{i}\left(x_{i}\right) \mathrm{d} \Phi_{i}\left(x_{i}\right)+f_{i} .
\end{gathered}
$$


The first-order optimality conditions on $k_{i}, K_{i}, P_{i}$ and $Q$ yield

$$
\alpha=\beta=\gamma=E B_{0}^{\prime}=E B_{i}^{\prime},
$$

where multipliers $\alpha, \beta$ and $\gamma$ are respectively associated with (A.21), (A.22) and (A.23) and

$$
\begin{aligned}
E B_{0}^{\prime}= & \int_{0}^{\bar{x}_{i}} \int_{-\infty}^{D-C_{i}\left(I_{i}\left(x_{i}\right)\right)} B_{0}^{\prime}\left(\sum_{j=1}^{n}\left(k_{j}+K_{j}\right)-z_{i}-C_{i}\left(I_{i}\left(x_{i}\right)\right)-Q\right) \mathrm{d} G_{i}\left(z_{i}\right) \mathrm{d} \Phi_{i}\left(x_{i}\right) \\
& +\int_{0}^{\bar{x}_{i}}\left[1-G_{i}\left(D-C_{i}\left(I_{i}\left(x_{i}\right)\right)\right)\right] B_{0}^{\prime}\left(\sum_{j=1}^{n}\left(k_{i}+K_{j}\right)-D-Q\right) \mathrm{d} \Phi_{i}\left(x_{i}\right), \\
E B_{i}^{\prime}= & \int_{0}^{\bar{x}_{i}} B_{i}^{\prime}\left(w_{i}-x_{i}+I_{i}\left(x_{i}\right)-P_{i}-k_{i}\right) \mathrm{d} \Phi_{i}\left(x_{i}\right) .
\end{aligned}
$$

At any point where $C_{i}\left(I_{i}\right)$ is differentiable, that is, when $I_{i} \neq I_{i}^{*}$, the first-order optimality condition on $I_{i}($.$) is written as$

$$
\begin{aligned}
& B_{i}^{\prime}\left(w_{i}-x_{i}+I_{i}\left(x_{i}\right)-P_{i}-k_{i}\right)+\alpha\left(1+\lambda_{i}^{k}\right) C_{i}^{\prime}\left(I_{i}\left(x_{i}\right)\right)-\gamma\left(1+\lambda_{i}^{c}+\lambda_{i}^{k}\right) \\
& -C_{i}^{\prime}\left(I_{i}\left(x_{i}\right)\right) E\left[B_{0}^{\prime} \mid C_{i}\left(I_{i}\left(x_{i}\right)\right)\right] \leqslant 0,=0 \quad \text { if } I_{i}\left(x_{i}\right)>0,
\end{aligned}
$$

where we use $B_{0}^{\prime}\left(\sum_{j=1}^{n}\left(k_{j}+K_{j}\right)-D-Q\right)=\beta(1+\mu)$, which as before results from the optimality condition on $D$.

When $I_{i}\left(x_{i}\right)>I_{i}^{*}$, we have $C_{i}^{\prime}\left(I_{i}\left(x_{i}\right)\right)=0$, and (A.25) gives

$$
B_{i}^{\prime}\left(w_{i}-x_{i}+I_{i}\left(x_{i}\right)-P_{i}-k_{i}\right)=\gamma\left(1+\lambda_{i}^{c}+\lambda_{i}^{k}\right)
$$

Since $B_{i}^{\prime \prime}<0,\left(\right.$ A.26) implies that $I_{i}\left(x_{i}\right)=x_{i}-d_{i}^{1}$ with

$$
B_{i}^{\prime}\left(w_{i}-d_{i}^{1}-P_{i}-k_{i}\right)=\gamma\left(1+\lambda_{i}^{c}+\lambda_{i}^{k}\right)
$$

When $0<I_{i}\left(x_{i}\right)<I_{i}^{*}$, we have $C_{i}^{\prime}\left(I_{i}\left(x_{i}\right)\right)=1$ and (A.25) gives

$$
\begin{aligned}
& B_{i}^{\prime}\left(w_{i}-x_{i}+I_{i}\left(x_{i}\right)-P_{i}-k_{i}\right)+\alpha\left(1+\lambda_{i}^{k}\right)-\gamma\left(1+\lambda_{i}^{c}+\lambda_{i}^{k}\right) \\
& \quad=E\left[B_{0}^{\prime} \mid C_{i}=I_{i}\left(x_{i}\right)\right]
\end{aligned}
$$

which yields

$$
B_{i}^{\prime}\left(w_{i}-x_{i}+I_{i}\left(x_{i}\right)-P_{i}-k_{i}\right)=\gamma \lambda_{i}^{c}+E\left[B_{0}^{\prime} \mid C_{i}=I_{i}\left(x_{i}\right)\right]
$$


Differentiating (A.28) gives

$$
\frac{\mathrm{d} I_{i}}{\mathrm{~d} x_{i}}=\frac{B_{i}^{\prime \prime}\left(w_{i}-x_{i}+I_{i}\left(x_{i}\right)-P_{i}-k_{i}\right)}{B_{i}^{\prime \prime}\left(w_{i}-x_{i}+I_{i}\left(x_{i}\right)-P_{i}-k_{i}\right)-\left.\frac{\partial E\left[B_{0}^{\prime} \mid C\right]}{\partial C}\right|_{C=I_{i}\left(x_{i}\right)}} \in(0,1) .
$$

Hence $\mathrm{d} I_{i} / \mathrm{d} x_{i} \in(0,1)$ when $x_{i} \in\left(d_{i}^{0}, I_{i}^{*}+d_{i}^{1}\right)$ where $d_{i}^{0}$ is such that

$$
B_{i}^{\prime}\left(w_{i}-d_{i}^{0}-P_{i}-k_{i}\right)=\gamma \lambda_{i}^{c}+E\left[B_{0}^{\prime} \mid 0\right],
$$

and we have $I_{i}\left(x_{i}\right)=0$ if $x_{i} \in\left[0, d_{i}^{0}\right]$. Using (A.27) and (A.28) allows us to write

$$
\begin{aligned}
E B_{i}^{\prime}= & \int_{0}^{d_{i}^{0}} B_{i}^{\prime}\left(w_{i}-x_{i}-P-k_{i}\right) \mathrm{d} \Phi_{i}\left(x_{i}\right)+\int_{d_{i}^{0}}^{I_{i}^{*}+d_{i}^{1}} B_{i}^{\prime}\left(w_{i}-x_{i}+I_{i}\left(x_{i}\right)-P_{i}-k_{i}\right) \mathrm{d} \Phi_{i}\left(x_{i}\right) \\
& +\left[1-\Phi_{i}\left(I_{i}^{*}+d_{i}^{1}\right)\right] B_{i}^{\prime}\left(w_{i}-d_{i}^{1}-P_{i}-k_{i}\right) \\
= & \int_{0}^{d_{i}^{0}} B_{i}^{\prime}\left(w_{i}-x_{i}-P_{i}-k_{i}\right) \mathrm{d} \Phi_{i}\left(x_{i}\right)+\int_{d_{i}^{0}}^{I_{i}^{*}+d_{i}^{1}}\left\{\gamma \lambda_{i}^{c}+E\left[B_{0}^{\prime} \mid I_{i}\left(x_{i}\right)\right]\right\} \mathrm{d} \Phi_{i}\left(x_{i}\right) \\
& +\gamma\left(1+\lambda_{i}^{c}+\lambda_{i}^{k}\right)\left[1-\Phi_{i}\left(I_{i}^{*}+d_{i}^{1}\right)\right] .
\end{aligned}
$$

If $d_{i}^{0}=0$,we would have

$$
\begin{aligned}
E B_{i}^{\prime}= & \int_{0}^{I_{i}^{*}+d_{i}^{1}}\left\{\gamma \lambda_{i}^{c}+E\left[B_{0}^{\prime} \mid I_{i}\left(x_{i}\right)\right]\right\} \mathrm{d} \Phi_{i}\left(x_{i}\right) \\
& +\gamma\left(1+\lambda_{i}^{c}+\lambda_{i}^{k}\right)\left[1-\Phi_{i}\left(I_{i}^{*}+d_{i}^{1}\right)\right]<\gamma,
\end{aligned}
$$

where the last inequality follows from $E\left[B^{\prime}{ }_{0} \mid I_{i}\left(x_{i}\right)\right]<\gamma\left(1+\lambda_{i}^{k}\right)$ for all $x_{i} \in\left[0, I_{i}^{*}+d_{i}^{1}\right.$ ). Eq. (A.30) would then contradict (A.24). We thus have $d_{i}^{0}>0$.

\section{Proof of Proposition 5}

The proof is similar to the proof of Proposition 4. In Part 1, (A.14) is replaced by

$$
K_{i}-\int_{0}^{\bar{I}_{i}}\left[C_{i}\left(I_{i}\right)+Z_{i}\left(I_{i}\right)-Z_{i}\left(I_{i}-C_{i}\left(I_{i}\right)\right)\right] \mathrm{d} \Gamma_{i}\left(I_{i}\right) .
$$


Let $\alpha$ and $\beta$ be Lagrange multipliers respectively associated with (A.31) and (A.15). The first-order optimality conditions associated with $D$ and $C_{i}($.$) still$ yield (A.18), while (A.19) is replaced by

$$
\begin{aligned}
A_{i}\left(I_{i}, C_{i}\left(I_{i}\right)\right) & \geqslant 0 \text { if } C_{i}\left(I_{i}\right)=I_{i}>0, \\
& =0 \text { if } 0<C_{i}\left(I_{i}\right)<I_{i}, \\
& \leqslant 0 \text { if } C_{i}\left(I_{i}\right)=0<I_{i} .
\end{aligned}
$$

where

$$
A_{i}(I, C) \equiv \alpha\left[1+Z_{i}^{\prime}(I-C)\right]-E\left[B_{0}^{\prime} \mid C\right],
$$

and $E\left[B^{\prime}{ }_{0} \mid C\right]$ is still given by (A.20). Note that

$$
\alpha=E B_{0}^{\prime}=\int_{0}^{\bar{I}_{i}} E\left[B_{0}^{\prime} \mid C_{i}\left(I_{i}\right)\right] \mathrm{d} \Gamma_{i}\left(I_{i}\right)>E\left[B_{0}^{\prime} \mid 0\right] .
$$

Hence we have $A_{i}(I, 0)=\alpha\left[1+Z_{i}^{\prime}(I)\right]-E\left[B_{0}^{\prime} \mid 0\right]>\alpha Z_{i}^{\prime}(I)>0$, which gives $C_{i}\left(I_{i}\right)>0$ if $I_{i}>0$. For all $I_{i}$ such that $0<C_{i}\left(I_{i}\right)<I_{i}$, we have $A_{i}\left(I_{i}, C_{i}\left(I_{i}\right)\right)=0$, which gives

$$
\frac{\mathrm{d} C_{i}}{\mathrm{~d} I_{i}}=\frac{\alpha Z_{i}^{\prime \prime}\left(I_{i}-C_{i}\right)}{\alpha Z_{i}^{\prime \prime}\left(I_{i}-C_{i}\right)+\frac{\partial E\left[B_{0}^{\prime} \mid C_{i}\right]}{\partial C_{i}}} \in(0,1),
$$

and we have $C_{i}\left(I_{i}\right)<I_{i}$ if $A_{i}\left(I_{i}, I_{i}\right)=\alpha\left[1+Z_{i}^{\prime}(0)\right]-E\left[B^{\prime}{ }_{0} \mid I_{i}\right]<0$, which implies $I_{i}>I_{i}^{* * *}$ where $I_{i}^{* * *}$ is given by $\alpha\left[1+Z_{i}^{\prime}(0)\right]-E\left[B^{\prime}{ }_{0} \mid I_{i}^{* * *}\right]=0$. We have $C_{i}\left(I_{i}\right)=I_{i}$ when $I_{i} \leqslant I_{i}^{* * *}$. In Part 2, (A.21) and (A.23) are respectively replaced by

$$
K_{i}=\int_{0}^{\bar{x}_{i}}\left[C_{i}\left(I_{i}\left(x_{i}\right)\right)+Z_{i}\left(I_{i}\left(x_{i}\right)\right)-Z_{i}\left(I_{i}\left(x_{i}\right)-C_{i}\left(I_{i}\left(x_{i}\right)\right)\right)\right] \mathrm{d} \Phi_{i}\left(x_{i}\right),
$$

and

$$
P_{i}=\int_{0}^{\bar{x}_{i}}\left[\left(1+\lambda_{i}^{c}\right) I_{i}\left(x_{i}\right)+Z_{i}\left(I_{i}\left(x_{i}\right)\right)\right] \mathrm{d} \Phi_{i}\left(x_{i}\right)+f_{i},
$$


while (A.22) is unchanged. Let $\alpha, \beta$ and $\gamma$ be the Lagrange multipliers, which are respectively associated with (A.32), (A.22) and (A.33). (A.24) still holds and (A.25) is replaced by

$$
\begin{aligned}
& B_{i}^{\prime}\left(w_{i}-x_{i}+I_{i}\left(x_{i}\right)-P_{i}-k_{i}\right)+\alpha\left[C_{i}^{\prime}\left(I_{i}\left(x_{i}\right)\right)+Z_{i}^{\prime}\left(I_{i}\left(x_{i}\right)\right)-Z_{i}^{\prime}\left(I_{i}\left(x_{i}\right)\right.\right. \\
& \left.-C_{i}\left(I_{i}\left(x_{i}\right)\right)\right)\left(1-C_{i}^{\prime}\left(I_{i}\left(x_{i}\right)\right)\right]-\gamma\left(1+\lambda_{i}^{c}+Z_{i}^{\prime}\left(I_{i}\left(x_{i}\right)\right)\right) \\
& -C_{i}^{\prime}\left(I_{i}\left(x_{i}\right)\right) E\left[B_{0}^{\prime} \mid C_{i}\left(I_{i}\left(x_{i}\right)\right)\right] \leqslant 0,=0 \quad \text { if } I_{i}\left(x_{i}\right)>0 .
\end{aligned}
$$

The remaining part of the proof then straightforwardly replicates the proof of Proposition 4. In particular, (A.28) still holds when $0<I_{i}\left(x_{i}\right)<I_{i}^{* *}$, which gives $\mathrm{d} I_{i} / \mathrm{d} x_{i} \in(0,1)$ in that case. When $I_{i}\left(x_{i}\right)>I_{i}^{* *}$, we have

$$
B_{i}^{\prime}=\left(w_{i}-x_{i}+I_{i}\left(x_{i}\right)-P_{i}-k_{i}\right)=\gamma\left[1+\lambda_{i}^{c}+Z_{i}^{\prime}\left(I_{i}\left(x_{i}\right)-C_{i}\left(I_{i}\left(x_{i}\right)\right)\right)\right],
$$

which also gives $\mathrm{d} I_{i} / \mathrm{d} x_{i} \in(0,1)$. Function $I_{i}\left(x_{i}\right)$ has a non-differentiable point when $I_{i}\left(x_{i}\right)=I_{i}^{* * *}$, which is reached at $x_{i}=d_{i}^{1}$ and a straightforward computation gives $I_{i+}^{\prime}\left(d_{i}^{l}\right)>I_{i-}^{\prime}\left(d_{i}^{l}\right)$.

\section{About the Authors}

Pierre Picard is Professor at Ecole Polytechnique (France).

Jean Pinquet is Associate Professor at University Paris-Ouest Nanterre-La Défense and researcher at Ecole Polytechnique (France). 